\title{
Funciones y disfunciones de las comisiones de la asamblea legislativa
}

\author{
Oscar Martínez Peñate
}

Resumen

Este artículo analiza los procedimientos para la conformación de la Asamblea Legislativa, tanto estructural como funcional. Expone los actos ilícitos de algunos partidos para la selección de la Junta Directiva. Además, corrobora que no existen parámetros ni criterios establecidos para la selección de los diputados que integrarán cada comisión. Asimismo, no existe en el reglamento interior de la Asamblea Legislativa nada escrito respecto al funcionamiento interno de las comisiones. Esta situación se agrava dado que existe una falta de control y supervisión del Poder Legislativo, lo cual conduce a su ineficiencia, tortuguismo, ineptitud y autoritarismo. De allí la necesidad de modificar artículos inespecíficos y garantizar el control de la Asamblea Legislativa sobre los Poderes Ejecurivo y Judicial para, de una vez por todas, impedir la utilización de los tres Poderes por parte de la oligarquía.

La Junta Directiva de la Asamblea Legislativa de El Salvador - conocida en otros países como Mesa o Directorio-, supuestamente es una autoridad colegiada que debería estar integrada por una representación proporcional de diputados pertenecientes a todas las fracciones políticas, es decir, que refleje la voluntad popular. Al partido que obtuviere el mayor porcentaje de diputados automáticamente se le concedería la presidencia de la Junta Directiva, previa presentación de una terna y de la cual se elegiría al presidente. 


\section{Cuadro 1 \\ Reformas a la composición de la Junta \\ Directiva de la Asamblea Legislativa de El Salvador de 1984 a 1997}

\begin{tabular}{lcrrr}
\hline & \multicolumn{4}{c}{ Fecha de las reformas } \\
Cargos & $1984^{1}$ & $1991^{2}$ & $1994^{3}$ & $1997^{4}$ \\
\hline Presidente(a) & 1 & 1 & 1 & 1 \\
Vicepresidentes(as) & 2 & 4 & 4 & 4 \\
Secretarios(as) & 6 & 7 & 5 & 6 \\
\hline Total & 9 & 12 & 10 & 11 \\
\hline
\end{tabular}

Fuente:

1. Diario Oficial, San Salvador, 20 de enero de 1984. No 15, Tomo 282, p. 2.

2. Ibíd., 27 de mayo de 1991, No 95, Tomo 311, p. 3.

3. Ibíd., 2 de junio de 1994, No 102, Tomo 323, p. 3.

4. La Asamblea Legislativa de la República de El Salvador, Decreto No 2, San Salvador, Salón Azul del Palacio Legislativo, 5 de mayo de 1997.

\section{Junta Directiva de la Asamblea Legislativa}

\subsection{Traición y autoritarismo}

En la legislatura de 1994-1997, la Junta Directiva tuvo tres puestos vacantes - una vicepresidencia y dos secretarías - debido a que el Partido Demócrata Cristiano se abstuvo de ocuparlos. Además, sólo estuvieron representados los partidos de derecha; el FMLN no formó parte de ella a pesar de haberle asistido el derecho.

El FMLN condicionó su participación a cambio de la modernización del Poder Legislativo. Entre las condiciones esgrimidas por el Frente se pueden mencionar las reformas en el reglamento interior de la Asamblea Legislativa, la revisión de la integración y el mejoramiento del funcionamiento de las comisiones legislativas, así como el aumento en el número de éstas.
Por otra parte, el FMLN no participó debido a que ARENA puso en ejercicio una medida política para imponer más miembros de su partido en la Junta Directiva. ARENA obtuvo, en las elecciones de 1994, 39 diputados, lo cual representaba el 46.4 por ciento del total de 84 legisladores; el FMLN logró 21 diputados, es decir, el 25 por ciento. No obstante, ARENA se agencio, sin tener derecho a ello, el 50 por ciento +1 no sólo en la composición de la Junta Directiva sino también en las comisiones legislativas. ARENA le atribuyó al FMLN únicamente el 20 por ciento ${ }^{1}$.

\subsection{El Partido Demócrata fue producto del oportunismo}

La posición del FMLN fue aprovechada por dos de sus fuerzas políticas integrantes: el ex Ejército Revolucionario del Pueblo (ERP), más tarde conocido como Expresión Revolucionaria del Pueblo, y la Resistencia Nacional (RN). Ambas se ofrecieron para ocupar los dos asientos que ARENA le otorgaba al FMLN en la Junta Directiva. De tal forma que ambas organizaciones decidieron formar parte de la Junta Directiva sin ningún tipo de cuestionamiento, lo cual condujo a la separación de éstas fuerzas como miembros del FMLN. Con esta acción, de los 21 diputados que tenía la izquierda sólo le quedaron 14, pues 7 decidieron cambiar de posición ideológica y se pasaron a la derecha. Dentro de este orden, los partidos políticos de derecha le cedieron a la diputada Ana Guadalupe Martínez el cargo de vicepresidenta y a Eduardo Sancho el de secretario de la Junta Directiva².

Posteriormente, el Ejército Revolucionario del Pueblo cambió de nombre y se autodenominó Expresión Renovadora del Pueblo, lo que les permitió conservar la misma sigla -ERP. El ERP, la Resistencia Nacional (RN) y el Movimiento Nacional Revolucionario (MNR) ${ }^{3}$ formaron el Partido Demócrata (PD). La primera acción que llevaron a cabo

1. ARENA dispuso la siguiente distribución de las fracciones legislativas en la composición de la Junta Directiva para la legislatura 1994-1997, independientemente de los resultados obtenidos por los partidos políticos en las elecciones de 1994: Cinco diputados del partido ARENA (la presidenta tuvo dos votos), representaba el "50 por ciento + 1". Dos diputados del partido FMLN, que representaba el 20 por ciento. Dos diputados del Partido Demócrata Cristiano. Un diputado del Partido de Conciliación Nacional. En la legislatura de 1997-2000 se suprimió el doble voto del presidente, el cual se sustituyó con la creación de una secretaría más en la Junta Directiva.

2. Torres-Rivas, Edelberto. El tamaño de nuestra democracia, San Salvador, ISTMO, 1992, p. 85.

3. EI MNR fue cancelado por el Tribunal Supremo Electoral por no haber alcanzado el uno por ciento de los votos válidos en las elecciones de marzo de 1994. Según lo estipulaba el Código Electoral 1993, en el Artículo 182, numeral 3. 
como partido político en formación, en aquella época, fue la retribución del favor a ARENA por haberle cedido los dos asientos en la Junta Directiva. Casi de inmediato le brindaron, públicamente y con despliegue propagandístico, el apoyo al proyecto económico y político de ARENA con la firma del llamado Pacto de San Andrés y, dentro de este contexto. también su respaldo para que este partido aumentara tres puntos al Impuesto al Valor Agregado (IVA).

\subsection{La izquierda no se dividió, se autodepuró}

Estas escisiones o atomizaciones tanto de la derecha como de la izquierda son consueludinarias en el régimen de partidos políticos salvadoreños y se deben, entre otras razones, a la falta de mecanismos que permitan la práctica real de la democracia en el exterior e interior de los partidos políticos, igualmente a la ausencia de cohesión ideológica y la deficiente unidad orgánica. Según Edelberto Torres Rivas: "La tradición de partidos políticos es aún deficiente, porque no tienen fuerzas orgánico-ideológicas para trascender las tendencias al fraccionalismo, al personalismo, al oportunismo de la coyuntura"'.

En este mismo orden, en El Salvador, la Junta Directiva se elige al inicio de cada legislatura, el día primero de mayo. Se supone que la elección es una decisión soberana de los diputados, sin interferencias externas, por ejemplo, del Poder Ejecutivo o de las cúpulas de los partidos políticos.

Pero, debido a que el reglamento interior de la Asamblea Legislativa de El Salvador apenas está constituido por 10 cuartillas mecanografiadas en ambos lados, en papel bond tamaño carta, cuyo reducido texto contiene sólo sesenta y nueve artículos de generalidades y vaguedades, se permiten, toleran y fomentan las arbitrariedades e injusticias. La excusa o argumento de los partidos de derecha, particularmente de ARENA, es que como el reglamento no lo contiene o no lo prohíbe entonces, dentro de esta lógica, cualquier hecho injusto o despótico es legal y está apegado al derecho.

Es importante hacer notar que la elección de la Junta Directiva de la legislatura 1997-2000, puso fin al reinado de la imposición y del autoritarismo que había instaurado el partido ARENA. A pesar del inconsistente reglamento interno de la asamblea, los partidos políticos de oposición obligaron a ARENA a establecer consenso, de tal forma que la Junta Directiva esta vez se eligió democráticamente.

La conformación de la Junta Directiva de la legislatura 1997-2000 surgió a través de un acta de compromiso firmada por todos los partidos políticos representados en la asamblea'.

Cuadro 2

Elección de la Junta Directiva por residuos de acuerdo con los datos obtenidos en las elecciones de 1997

\begin{tabular}{lcccccc}
\hline Partido político & Diputados & $\%$ & $\% \times 11 / 100$ & $1 / 11$ & $(\% \times 11 / 100) /(0.09) * 10$ & No. de diputados \\
\hline ARENA & 28 & 33.33 & 3.67 & 0.09 & 4.03 & 4 \\
FMLN & 27 & 32.14 & 3.54 & 0.09 & 3.89 & 4 \\
PCN & 11 & $13.0:$ & 1.44 & 0.09 & 1.58 & 1 \\
PDC & 7 & 8.33 & 0.92 & 0.09 & 1.01 & \\
PRSC & 3 & 3.57 & 0.39 & 0.09 & 0.43 & \\
PDC-PD & 3 & 3.57 & 0.39 & 0.09 & 0.43 & \\
CD & 2 & 2.38 & 0.26 & 0.09 & 0.29 & 0.29 \\
PLD & 2 & 2.38 & 0.26 & 0.09 & 0.14 & 11 \\
MU & 1 & 1.19 & 0.13 & 0.09 & 12.0 & \\
\hline Totales & 84 & 100 & $I 1.00$ & &
\end{tabular}

4. EL Partido Demócrata desempeñó el mismo rol que jugó el Partido Demócrata Cristiano, cuando éste último partido pactó a finales de 1979 con la Fuerza Armada "Salvadoreña" y los Estados Unidos, para formar parte de la junta de gobierno que reemplazaría a la junta revolucionaria.

5. FMLN, Convergencia Democrática y et al. "Acta de Compromiso", San Salvador, Partidos políticos representados en la Asamblea Legislativa, 2 de mayo de 1997. 
La elección de la Junta Directiva ha causado problemas para su conformación, por lo que se advierte la necesidad de una normativa que sea contemplada en el reglamento interno a fin de evitar contratiempos y disputas para constituirla. En el cuadro anterior se expone su integración a partir del residuo que cada partido tenga, de acuerdo con el número de diputados que conformen cada fracción política, para lo cual se toma como base el número de miembros que la conforman, en este caso sería de once miembros.

Con esta fórmula se obligaría a los partidos políticos pequeños a unirse para formar fracciones políticas que les permitan obtener o aumentar diputados en la integración de la Junta Directiva. Asimismo, contribuiría a lograr una mejor representación, coordinación y coherencia en el trabajo legislativo.

\section{Cuadro 3}

Procedimiento para la elección de la Junta Directiva de la Asamblea Legislativa de El Salvador

\begin{tabular}{ll}
\hline Miembros & \multicolumn{1}{c}{ Comisiones } \\
\hline Comisión Preparatoria
\end{tabular}

Comisión de Debates

1 Director $(r a)$

2 Secretarios(as)
Una vez electos, presidirán la sesión en lugar de la Comisión Preparatoria. Esta Comisión de Debates se constituirá en Comisión Revisora de Credenciales.

\section{Comisión Revisora de Credenciales}

Los mismos Miembros

Recibirá las credenciales de los diputados y las diputadas presentes de la comisión anterior, y examinarán y aceptarán, en su caso, dichas credenciales. Para tal revisión, el Director o la Directora de Debates suspenderá la sesión la cual se reanudará al concluir el examen de las Credenciales, a continuación se dará a conocer el informe de laComisión Revisora de Credenciales. Aprobado por el Pleno el informe de la Comisión Revisora de Credenciales se procederá a elegir, por mayoría de votos en forma nominal y pública, a los diputados y las diputadas que integrarán la Junta Directiva.

\section{Funciones de la Junta Directiva}

Las funciones de la Junta Directiva de la Asamblea Legislativa de El Salvador se encuentran establecidas en el Art.7 del reglamento interior de la Asamblea. La Junta Directiva se puede tipificar como el máximo organismo administrativo de la asamblea que posee atribuciones inherentes a su naturaleza, es decir, eminentemente administrativas.

A nivel general, las funciones de la Junta Directiva en El Salvador, según el reglamento interior, son, entre otras, llevar el presupuesto de la asamblea; seleccionar y reclutar al personal técnico, 
secretarial, etc.; mantener y desarrollar la infraestructura; proponer la agenda de la sesión plenaria; etc.

Entre las principales atribuciones de la Junta Directiva de El Salvador se pueden mencionar las siguientes: (a) cumplir y hacer cumplir el presente reglamento; (b) fijar, a su juicio, a las comisiones - legislativas - un plazo prudencial para la emisión de los dictámenes; (c)) llamar al orden a los diputados y las diputadas cuando durante sus intervenciones falten a lo establecido; cuando profieran palabras mal sonantes $u$ ofensivas al decoro de la asamblea o a los miembros de ésta, a los otros Órganos del Estado o de sus miembros, al de personas extrañas, y cuando, en cualquier forma, alteren el orden de los debates. (d) Conceder licencia a los diputados y las diputadas que necesiten ausentarse por más de cinco días; (e) nombrar, quitar, aceptar renuncias y conceder licencias a los empleados de la oficina (sic).

Por tanto, la "función principal de La Junta Directiva es dirigir la actividad administrativa $y$ legislativa", to que significa que no está por encima de las comisiones legislativas permanentes 0 especiales ni sobre los dipulados, ni mucho menos tiene funciones legislativas.

\subsection{Funciones del presidente de la Junta Di- rectiva}

Entre las funciones del presidente de la Junta Directiva estipuladas en el reglamento interior de la Asamblea Legislativa de El Salvador, no se encuentran especificadas las siguientes: presidir las sesiones plenarias; conducir los debates parlamentarios; indicar a la asamblea el punto o los puntos que deben discutirse; recibir las votaciones corrientes y declarar la aprobación o rechazo de un asunto; declarar el resultado de las votaciones; dar a conocer los proyectos de ley presentados e indicar su naturaleza; la no obligación del presidente de formar parte de una comisión legislativa permanente; la libertad de asistir a las sesiones de las comisiones con derecho a voz pero pero no a voto; asistir como simple diputado a las sesiones de su respectiva fracción legislativa”; ser miembro de asociaciones parlamentarias latinoamericanas e internacionales; representar a la Asamblea Legislativa en el extranjero; la descentralización de los poderes administrativos; el doble voto y la tipificación de los casos en que debe usarse.

\section{Estructura de los comités legislativos}

Las comisiones o comités legislativos por lo general pueden clasificarse en:

A. Comisiones permanentes (standing committees)

B. Comisiones especiales (select committees)

C. Comisiones mixtas, interpalamentarias o intercamerales (joint committees)

D. Comisiones mixtas paritarias (conference committees)

E. Comisión general, comisión plenaria o comité del pleno(commission plénière)

Tanto la clasificación como la estructura y el funcionamiento sc encuentran establecidos en el respectivo reglamento interno de la asamblea y éste varía de Parlamenteo en Parlamento.

\section{A. Comisiones permanentes (standing committees)}

Estas comisiones surgieron en algunos Parlamentos en la segunda mitad del siglo pasado (Inglaterra, Estados Unidos, etc.), sin embargo, su institucionalización generalizada se produce casi inmediatamente después de la Primera Guerra Mundial. Su factor causal radica en que el comité del pleno mostraba insuficiencia e incapacidad para atender problemas y proyectos de ley cada vez más complicados, voluminosos y de diferentes tópicos, y paralelamente a esta situación el Estado asumía nuevas funciones.

Las comisiones permanentes las constituyen los subgrupos y en cada uno los diputados se dividen las tareas legislativas; éstas no tienen una existencia definida y sesionan regularmente todas las semanas. Por el trabajo y las funciones que cumplen se puede

6. Asamblea Legislativa de El Salvador. Manual del Diputado, S.l.i., S.p.i., fotocopia del documento, S.f., p. 2.

7. Ramírez Altamirano, Marina, Cfr. Manual de procedimientos legislativos, San José, IJSA, 1994, pp. 56 y 57. 


\section{Cuadro 4 \\ Atribuciones de la presidencia y de las vicepresidencias de la Junta Directiva de la Asamblea Legislativa de El Salvador}

De la presidencia y las vicepresidencias

(a) Abrir, suspender, reanudar y cerrar las sesiones.

(b) Convocar para sesión ordinaria, extraordinaria o solemne, así como para las sesiones de trabajo de las comisiones y de la Junta Directiva.

(c) Dirigir la discusión (sic) de los asuntos que se traten durante las sesiones y hacer las observaciones (sic) pertinentes.

(d) Conceder la palabra a los dipulados y las diputadas por el orden en que la hayan pedido.

(e) Conceder licencias a los diputados y las diputadas por motivos justificados y urgentes, hasta por cinco días consecutivos.

(ch) (sic) Determinar qué comisión o comisiones deben dictaminar sobre los asuntos sometidos al conocimiento de la asamblea.

(f) Suspender una sesión en casos de grave perlurbación.

(g) Solicitar a los espectadores abandonar el Salón Azul en caso de cualquier perturbación.

- En ausencia del presidente o de la presidenta le sustituirá el vicepresidente o la vicepresidenta que designe la Junta Directiva, y cn ausencia de estos, el secretario o la secretaria designado por la misma Junta Directiva. Este tendrá las mismas atribuciones del presidente o presidenta.

Fuente: Datos obtenidos del Reglamento Interior de la Asamblea Legislativa de El Salvador, Ed. cit., Art. 8 y 9.

afirmar que son la médula espinal del Poder Legislativo. En El Salvador son 14 y cada una está integrada con un promedio de 11 diputados, lo que significa que el 83 por ciento de los diputados perlenece a más de una comisión.

B. Comisiones especiales o ad hoc (select committees)

Son comisiones que se crean para abordar problemas muy específicos y leyes de carácter técnico, por lo general requieren de la colaboración de varias comisiones permanentes.

C. Comisiones mixtas, interparlamentarias o intercamerales (joint committees)

Se llaman comisiones mixtas porque están formadas por igual número de diputados y senadores tratan proyectos de interés común a ambas cámaras. Sólo pueden existir en Asambleas Legislativas bicamerales. La designación de sus miembros y funciones está regida por los mismos procedimientos de las comisiones permanentes. Estas comisiones no tienen competencias legislativas, no obstante. desempeñan un papel importante en el funcionamiento de la asamblea ${ }^{8}$.

D. Comisiones mixtas paritarias (conference committees)

Estas comisiones son similares a las comisiones mixtas en su composición, la diferencia estriba en que las comisiones mixtas paritarias se crean con el objetivo de resolver diferencias relacionadas con la redacción de algún texto o, simplemente, para cumplir el mandato de elaborar un texto común sobre algún tópico que se encuentre en discusión. Estas se disuelven automáticamente cuando la comisión se ha puesto de acuerdo en la redacción definitiva del texto y es aprobado por una de las cámaras en sesión plenaria.

8. Claire-Emmanuelle Longuet. Le Congrès des Etats-Unis -Que sais-je-, París, Presses Universitaires de France, 1989, p. 79. 
E. Comisión general, comisión plenaria o comilé del pleno (commission plénière)

Esta fue la comisión originaria y la forma de funcionamiento en la génesis del Poder Legislativo, es decir, el plenario era una sola comisión en donde se abordaban diferentes problemas de naturaleza distinta. En algunas Asambleas Legislativas bicamerales se crea la comisión general interparlamentaria, la cual es una variante de la comisión general con la diferencia de que está constituida por todos los diputados y senadores del Poder Legislativo.

En la actualidad ya no es la norma de trabajo sino la excepción. El plenario de la Asamblea Legislativa se convierte en comité del pleno o comisión general, en casos o situaciones que ameriten su formación.

\subsection{Otras clasificaciones de las comisiones}

En forma general, las comisiones legislativas pueden clasificarse también en permanentes y especiales o selectas. Las permanentes están integradas por los diputados de las diferentes fracciones políticas y son consideradas como el eje fundamental del proceso legislativo. Las especiales son establecidas por la Asamblea Legislativa para abordar asuntos específicos, igualmente determina quiénes serán sus miembros, su mandato y tiempo La existencia de ésta termina en el momento de presentar su informe.

Las comisiones se pueden clasificar en dos tipos: legislativa, que intervienen en el procedimiento legislativo, y no legislativa, que no intervienen en el proceso de elaboración de la ley, sino que por lo general cumplen funciones de carácter administrativo. Por otro lado, también se tipifican como horizontales cuando:

Estas comisiones, además de conocer sobre ciertos asuntos específicos, deben emitir su dictamen sobre materia correspondiente a otras comisiones desde el punto de vista en el que están especializadas: la comisión de asuntos

\section{Funciones de las comisiones permanentes}

Entre las funciones de las comisiones legislativas permanentes está, por ejemplo, la elaboración de proyectos de ley, el estudio y la discusión de aquellos que le son remitidos con el propósito de sancionarlos con la emisión de un dictamen, a fin de que posteriormente se presenten a la plenaria para su respectivo debate. El mismo procedimiento se realiza con las piezas de correspondencia aunque, en algunos casos, éstas no pasen al plenario para su discusión sino que sean enviadas directamente a las oficinas gubernamentales idóneas y pertinentes a la problemática que contenga cada una.

También entre sus funciones se puede mencionar la realización de audiencias a personas y grupos sociales interesados en algún proyecto de ley o

9. Pizzorusso, Alessandro. Lecciones de Derecho Constitucional, Madrid, Centro de Estudios Constitucionales, Tomo I. 1984, p. 271.

10. Friedrich, Carl J., Cfr. Gobierno constitucional y democracia, Madrid, Instituto de Estudios Políticos, 1975, p. 159. 
alguna pieza de correspondencia, para permitirle la participación a la ciudadanía y tomarla en cuenta a la hora en que la comisión tome alguna determinación. Todo este proceso se efectúa de cara a la sociedad y no a sus espaldas, por lo tanto, las reuniones de las comisiones no pueden ser secretas, clandestinas o privadas, ni tampoco se debe prohibir a los medios de comunicación su presencia en las sesiones.

Asimismo le corresponde estudiar detalladamente y revelar, en un plazo determinado, las memorias sobre las labores anuales de los ministerios que le corresponda por afinidad de especialidad o materia a cada comisión. También debe crear subcomisiones y darles el mandato para la realización de la tarea por efectuar; controlar y supervisar la forma en que el Ejecutivo elabora y ejecuta los reglamentos que se crean a raíz de la aprobación de las leyes; solicitar informes a determinadas personas e instituciones; llamar a los ministros para que brinden información; interpelar e interrogar a los funcionarios públicos; llevar a cabo estudios de investigación sobre asuntos de interés nacional que tengan relación con su competencia; racionalizar la jurisdiccionalidad y agilizar el trabajo de acuerdo con la especialidad de cada comisión y cumplir el rol de intermediario o árbitro en los conflictos sociales.
La mediación del Ejecutivo es obvia en caso de conflicto; cuando la misma falla, la situación no queda rota, sino que liene en la comisión respectiva una nueva instancia de más alto nivel para la resolución del conflicto" ${ }^{\prime \prime}$

Las comisiones constituyen el medio por excelencia para cumplir y hacer cumplir la función de legislación y control del Poder Legislativo. En El Salvador, la única función que se exige a las comisiones, según el Artículo 15 del reglamento interior de la Asamblea Legislativa, es la siguiente:

Las comisiones emitirán dictámenes razonando sus acuerdos y propuestas. Darán cuenta del desarrollo de su trabajo a la Junta Directiva, y sus decisiones se tomarán por mayoría de votos de sus miembros.

Por otra parte, a nivel general existe coincidencia entre las comisiones legislativas permanentes y los ministerios en que se divide el gobiemo, con el fin de garantizar la función de un efectivo control y supervisión del Ejecutivo sin que ésta signifique menoscabo de la independencia de poderes. Esta coincidencia propicia un mayor acercamiento y desarrollo de relaciones y vínculos entre los legisladores y funcionarios públicos, lo cual favorece la coordinación y colaboración entre los dos Poderes del Estado.

\section{Cuadro 5}

Correspondencia entre las comisiones legislativas y los ministerios del Gobierno

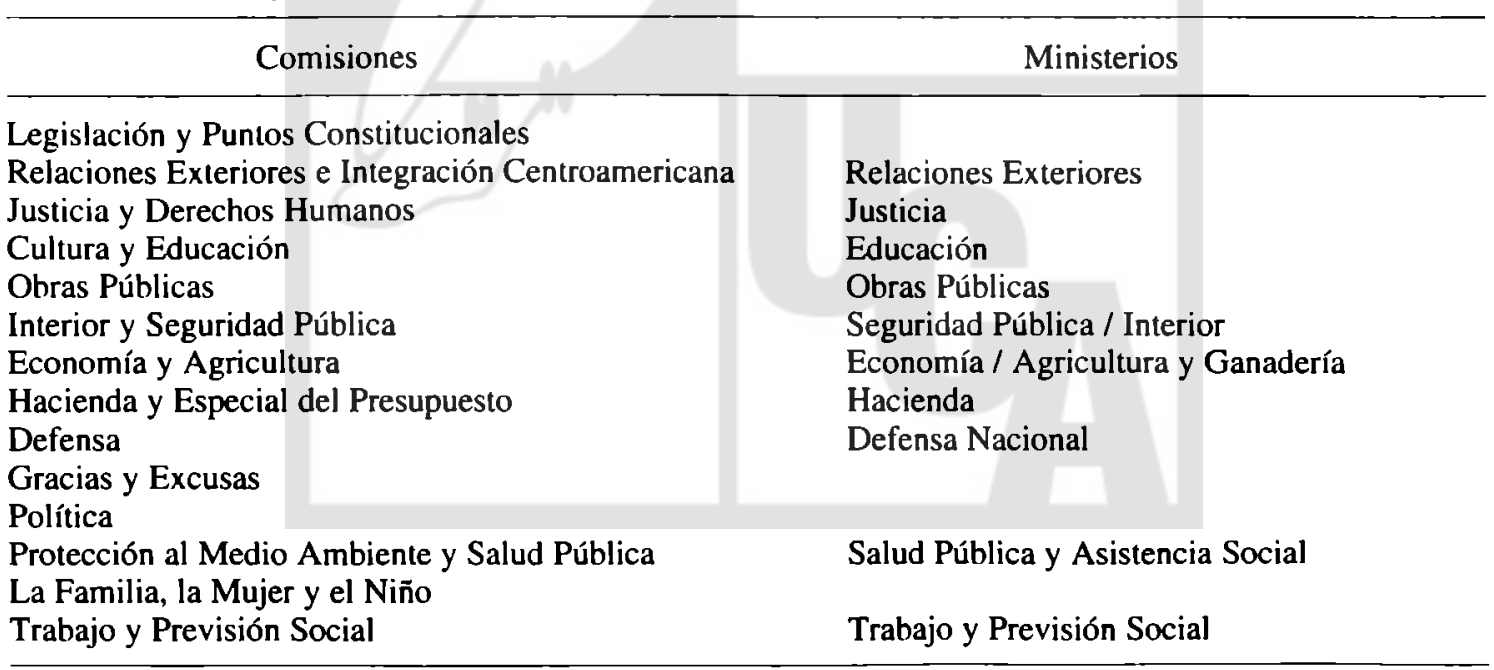

11. Vial Saavedra, Alejandro. "Informe preliminar sobre los parlamentos de Argentina, Chile y Uruguay; la necesidad de su fortalecimiento institucional", Revista Paraguaya de Sociología, Asunción, Centro Paraguayo de Estudios Sociológicos, No 90, mayo-agosto de 1994, p. 111. 
En El Salvador, el control y la supervisión del Poder Legislativo es prácticamente nulo, así como la existencia de mecanismos que aseguren una coordinación entre la Asamblea Legislativa y el Gobierno, aunque exista cierto paralelismo entre las comisiones y los ministerios. Esta situación se ha debido, primero a causa de la historia de dictaduras que han "gobernado" el país y, segundo, porque los partidos oficiales de derecha han tenido la mayoría de diputados en la asamblea y han tomado decisiones y creado leyes de forma autoritaria, de tal forma que han actuado en calidad de "aplanadora", aplastando los intereses del pueblo salvadoreño.

\section{División del trabajo en las comisiones}

\subsection{Elección de los miembros de las comisiones}

En algunos países, la elección de los diputados que conforman las comisiones tiene como base el mantenimiento de la proporporcionalidad que posee cada fracción política en la Asamblea Legislativa, es decir, que las comisiones reflejan la composición numérica, política e ideológica del Poder Legislativo. Por consiguiente, los partidos políticos que tienen menos diputados obtienen un número reducido de miembros en las comisiones, de esta manera, quienes tienen más curules obviamente alcanzan más en ellas; por otro lado, algunas fracciones políticas no pueden tener miembros en todas las comisiones.

La elección de los miembros de las comisiones se realiza, por regla general, al principio de cada legislatura y permanecen en ellas el tiempo que dura la legislatura; ésta es una decisión que corresponde al plenario legislativo. En este mismo sentido, una vez establecido el número de diputados por comisión, cada fracción legislativa procede a la selección de diputados y a la elaboración de una lista de acuerdo con la protesión, oticio, capacidad, especialidad, experiencia previa o conocimientos que cada parlamentario posea. Posteriormente ésta se somete a votación por parte de la sesión plenaria en la que son electos.

Por tanto, esta situación puede dar cabida a contubernios entre las distintas fracciones y en el interior de ellas. Según el diputado Arturo Argumedo h., esta selección se realiza de la siguiente manera: "el criterio es que si alguien tiene cara de policía lo mandan a la comisión de seguridad pública, si alguien tiene carro o ha sido cobrador de un bus, entonces se va a la de transporte"; además, agrega, que "son criterios artesanales, criterios miserables, no hay un criterio para eso"'/2. En este mismo sentido, se le preguntó al diputado Walter René Araujo Morales cómo se constituyen las comisiones legislativas, él respondió que "por acuerdos políticos"'13. Carmen Elena Calderón de Escalón, diputada de ARENA (1991-1994, 19941997), nos relató cómo fue asignada a la comisión de hacienda en los términos siguientes:

Ustedes se podrán preguntar qué anda haciendo una especialista en hematología en la hacienda pública, y esta fue la misma pregunta que yo le hice al mayor Roberto D'Abuisson, cuando me dijo: tú te vas a hacer cargo de la comisión de hacienda. Mi primera pregunta fue: ¿cómo vas a creer que me voy hacer cargo de eso, si he estado nada más en la parte puramente de investigación? "No", me respondió, "sos política, la lógica política te va a ayudar, el que no sabe aprende", me dijo ${ }^{14}$.

En la legislatura salvadoreña de 1994-1997, ARENA impuso el mismo modelo de "representación" de la Junta Directiva a las comisiones. ARENA tuvo en ellas cinco diputados, el FMLN 2, el Partido Demócrata Cristiano 2 y el Partido de Conciliación Nacional 1. No obstante, esta configuración sufrió moditicaciones durante la legislatura debido a las razones siguientes: escisiones entre los diputados que tuvieron algunas fracciones; sentimiento de incompetencia por parte del diputado para integrar

12. Entrevista a Arturo Argumedo h, diputado del Partido Demócrata Cristiano, Secretario de la Comisión de Legislación y Puntos Constitucionales, 17 de octubre de 1996, en el Salón Azul de la Asamblea Legislativa.

13. Entrevista al diputado Walter René Araujo Morales, Presidente de la Comisión de Legislación y Puntos Constitucionales, 21 de octubre 1996, en su oficina de la Asamblea Legislativa.

14. Entrevista a Carmen Elena Calderón de Escalón, diputada de ARENA, Presidenta de la Comisión de Hacienda y Especial del Presupuesto, 17 de octubre de 1997, en su oficina en la Asamblea Legislativa. 
dos o tres comisiones simultáneamente por lo que decide permanecer en una o dos, o por la interferencia en los horarios de reunión de las comisiones.

En la Iegislatura de 1997-2000, a pesar de los vacíos que tiene el reglamento interior de la Asamblea Legislativa, se dio un paso hacia adelante pues, en esta oportunidad, la Junta Directiva ya no decidió cómo se estructurarían las comisiones sino que fueron los jefes de fracción los que se reunieron con ella y le entregaron las propuestas de los diputados que la conformarían; además, esta vez prevaleció el principio de la proporcionalidad y se tomaron en cuenta las profesiones, oficios, vocaciones, etc., de los diputados. Las comisiones fueron formadas de la manera siguiente: una comisión por diez diputados y siete suplentes (comisión políica), y trece comisiones por doce diputados. Por lo general, éstas fueron constituidas así: tres diputados de ARENA, tres del FMLN, dos del Partido de Conciliación Nacional, dos del Partido Demócrata Cristiano, uno de los partidos minoritarios y uno del Bloque Social Cristiano (BSC) ${ }^{15}$. Esta situación se logró principalmente porque ARENA en esta legislatura ya no pudo imponer su voluntad.

El número de diputados que integran las comisiones no es determinante para el buen funcionamiento del Poder Legislativo, por ejemplo, con la actual calidad de la mayoría de los diputados, el nivel de los técnicos y analistas legislativos, la falta de oficinas de investigación y especialización parlamentaria, la biblioteca deficiente, así como la actual normatividad que contiene el reglamento interior de la asamblea, no habría diferencia si las comisiones las formaran diez o cien dipulados cada una ya que el producto sería prácticamente el mismo.

En El Salvador, los partidos políticos proponen a la Junta Directiva la nómina de los diputados que formarán parte de las comisiones El nombramiento de los diputados que integrarán las comisiones no está debidamente normado y, al igual que casi todas las disposiciones que contiene el reglamento interior de la asamblea, es vago porque se constituye en una función de los parlamentarios que conforman la Junta Direcliva, la cual se basa y fundamenta en el voluntarismo y el libre arbitrio de sus miembros. Por ejemplo, según el reglamento interior de la Asamblea Legislativa, Artículo 7, literal f, es atribución de la Junta Directiva "nombrar en el número que estime conveniente, los dipulados y las diputadas que deban integrar las comisiones que establece el reglamento".

\subsection{Elección de las directivas de las comisiones legislativas}

La elección de los directivos de las comisiones legislativas en los parlamentos se efeclúa a partir del principio de la representatividad numérica que tengan las fracciones polílicas y la antigüedad - seniority - adquirida por los diputados, como miembros de ella, en las legislaturas anteriores. También puede realizarse de acuerdo con la voluntad de cada comisión, es decir, que la elección se realice mediante votaciones secretas en el interior de cada una, así se eligen a quienes obtengan mayoría absoluta de los miembros presentes en la comisión.

En El Salvador, según el reglamento interior de la Asamblea Legislativa, Artículo 13:

Las comisiones designarán entre sus miembros un presidente o una presidenta, un relator o una relatora y un secretario o una secretaria, teniendo los demás miembros la calidad de vocales, poniéndolo en conocimiento de la Junta Directiva.

Otra vez nos encontramos con un artículo muy vago. Por ejemplo, no hay especificación de parámetros, por lo cual la designación se realiza a Iravés de acuerdos políticos, negociaciones y cabildeos, no sólo entre las fracciones legislativas sino entre las dirigencias de los partidos políticos $y$, lo que es peor, esto ha ocurrido la mayoría de veces. Al no haber una normativa puede ocurrir cualquier cosa, de tal forma que cada tres años la elección de los miembros que presidirán las comisiones es una

15. La Asamblea Legislativa, Cfr. "Acuerdo No 44", San Salvador, Palacio Legislativo, 26 de mayo de 1997. 
verdadera disputa; a esta situación se le denomina coloquialmente "la piñata de los diputados".

"La piñata de los diputados" también comprende la dispula por la presidencia de las comisiones; las más codiciadas son la de hacienda y especial de presupuesto, legislación y puntos constitucionales, y la de economía y agricultura. Otro escenario se presentaría si se conocieran con anterioridad las presidencias a las que tendría derecho el partido que obtuviera la mayoría de diputados y cuáles las restantes.

Al respecto, se le formuló al diputado Alex René Aguirre Guevara (1994-1997, 1997-2000) la pregunta siguiente: ¿cómo se elige a los miembros directivos de la comisiones legislativas? "Este es un cabildeo que se hace con anlerioridad, porque yo podría decirles lo que debería de hacerse, pero esto es lo que realmente pasa" 16 . Después de todas las "negociaciones" se le da el toque "democrático", pues se eligen en el interior de cada comisión los directivos de las mismas; la elección del presidente se hace por mayoría simple, es decir, basta con el cincuenta por ciento más uno de los miembros. Sin embargo, el lugar que sirve de escenario de esta forma "democrática" para elegir a los directivos de la asamblea es la comisión política, es decir, en la "cocina" del recinto legislativo porque aquí es donde se "guisa" la elección de los altos funcionarios públicos, leyes, presupuesto, etc.

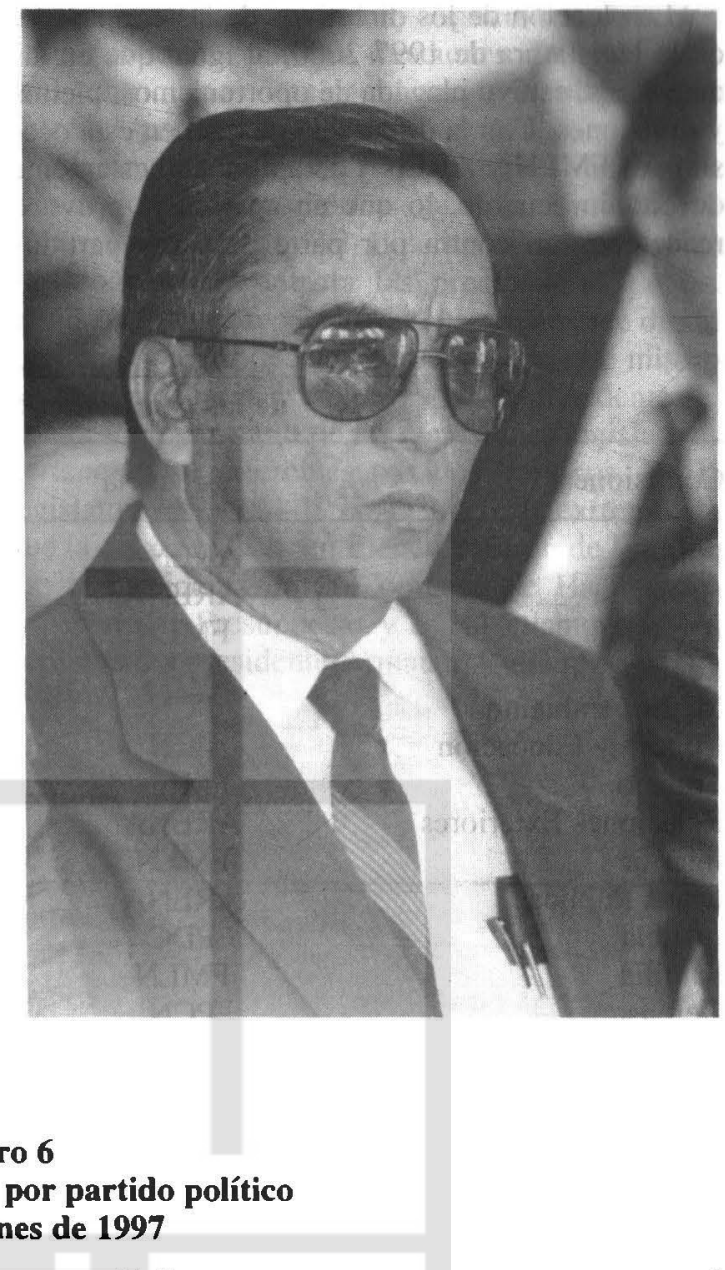

\begin{tabular}{lc}
\hline Partidos & Diputados \\
\hline ARENA & 28 \\
Convergencia Democrática & 2 \\
FMLN & 27 \\
Movimiento de Unidad & 1 \\
Partido de Conciliación Nacional & 11 \\
Partido Demócrata Cristiano & 7 \\
Partido Liberal Democrático & 2 \\
Partido de Renovación Social Cristiano & 3 \\
Partido Demócrata Cristiano & 3 \\
Partido Demócrata & 84 \\
\hline Total & \\
\hline
\end{tabular}

Fuente: Tribunal Supremo Electoral

16. Entrevista a Alex René Aguirte Guevara, diputado del Partido de Conciliación Nacional, Relator de la Comisión de Economía y Agricultura, el 15 de octubre de 1996 en la Asamblea Legislativa. 
La elección de los directivos de las comisiones en la legislatura de 1997-2000, al igual que en las anteriores, estuvo plagada de oportunismos, pleitos y divisiones. Con la diferencia de que, en esta ocasión, el FMLN y ARENA actuaron supuestamente de común acuerdo, lo que en apariencia provocó reacciones en contra por parte de otros partidos como, Conciliación Nacional y el Demócrata Cristiano. Sin embargo, ARENA también "negoció con estos mismos partidos la distribución de las presidencias de las comisiones"17. No obstante, al final, las fracciones obtuvieron cierto equilibrio en la distribución de las directivas de las comisiones legislativas.

\section{Cuadro 7}

Distribución de las directivas de las comisiones legislativas (1997-2000)

\begin{tabular}{lccc}
\hline Comisiones & Presidencia & Secretaría & Relatoría \\
\hline Política & ARENA & FMLN & PDC \\
Hacienda & ARENA & FMLN & PDC \\
Economía & FMLN & ARENA & PCN \\
Legislación & G-6" & PDC & FMLN \\
Medio Ambiente & PCN & G-6 & ARENA \\
Cultura y Educación & PCN & G-6 & FMLN \\
Trabajo & FMLN & ARENA & PDC \\
Relaciones Exteriores & ARENA & FMLN & PDC \\
Interior & FMLN & ARENA & PCN \\
Obras Públicas & FRENA & FMLN & PCN \\
Justicia & PDC & G-6 & ARENA \\
Familia & FMLN & ARENA & PCN \\
Defensa & PCN & PDC & ARENA \\
Gracias y Excusas & PDC & PCN & FMLN
\end{tabular}

* Grupo constituido por seis partidos minoritarios.

Gráfica 1

Distribución por partido de los puestos de las directivas en las comisiones

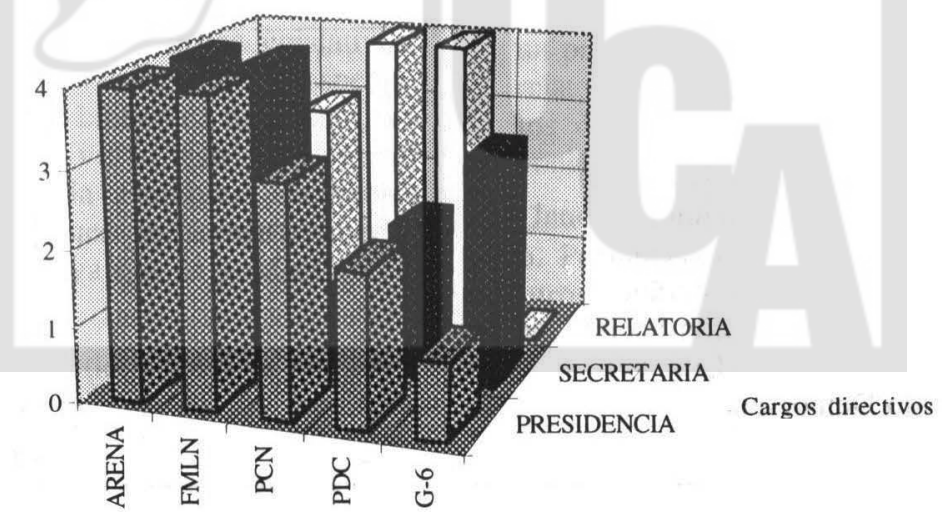

Partidos políticos

17. Laínez, Luis. "La oposición denuncia doble juego de ARENA en Asamblea", San Salvador, El Diario de Hoy, 22 de mayo de 1997, p. 6. 
A nivel teórico, este equilibrio en la distribución es el reflejo del que existe en el interior de la Asamblea Legislativa, principalmente entre ARENA y el FMLN, puesto que ninguno tiene las condiciones para imponer su voluntad, lo cual contribuye al proceso de democratización, por tanto, la negociación en el sentido positivo se vuelve imperante. Sin embargo, a nivel práctico, los partidos de derecha son la mayoría, por consiguiente, ARENA y sus partidos satélites seguirán sumiendo más a la población en la pobrcza y el desempleo.

Este cierto equilibrio en mención es más fortuito que el resultado de la aplicación de normas preestablecidas en el reglamento interior de la asamblea. Si se nonmara, por ejemplo, que las presidencias de las comisiones de Legislación y Puntos Constitucionales, de Hacienda y Especial del Presu- puesto, y la de Economía y Agricultura deberían estar presididas por las fracciones de oposición, esto contribuiría a una coordinación y colaboración entre el partido de gobierno y los partidos de oposición. Traducido en otros términos, permitiría una mejor coordinación y colaboración entre el Poder Legislativo y el Ejecutivo, porque si el partido oficial controla las presidencias de las comisiones antes mencionadas, es sumamente difícil hablar de independencia de Poderes. En este mismo orden, se debería establecer que el presidente, el relator y el secretario de las comisiones legislativas pertenezcan a diferentes partidos políticos. En la legislatura de 1994-1997 se llegó al extremo de que la diputada Carmen Elena Calderón de Escalón fue la presidenta de la Comisión de Hacienda y Especial del Presupuesto y es, al mismo ticmpo, hermana del presidente Armando Calderón Sol.

\section{Gráfica 2}

Resultados de las elecciones de 1997

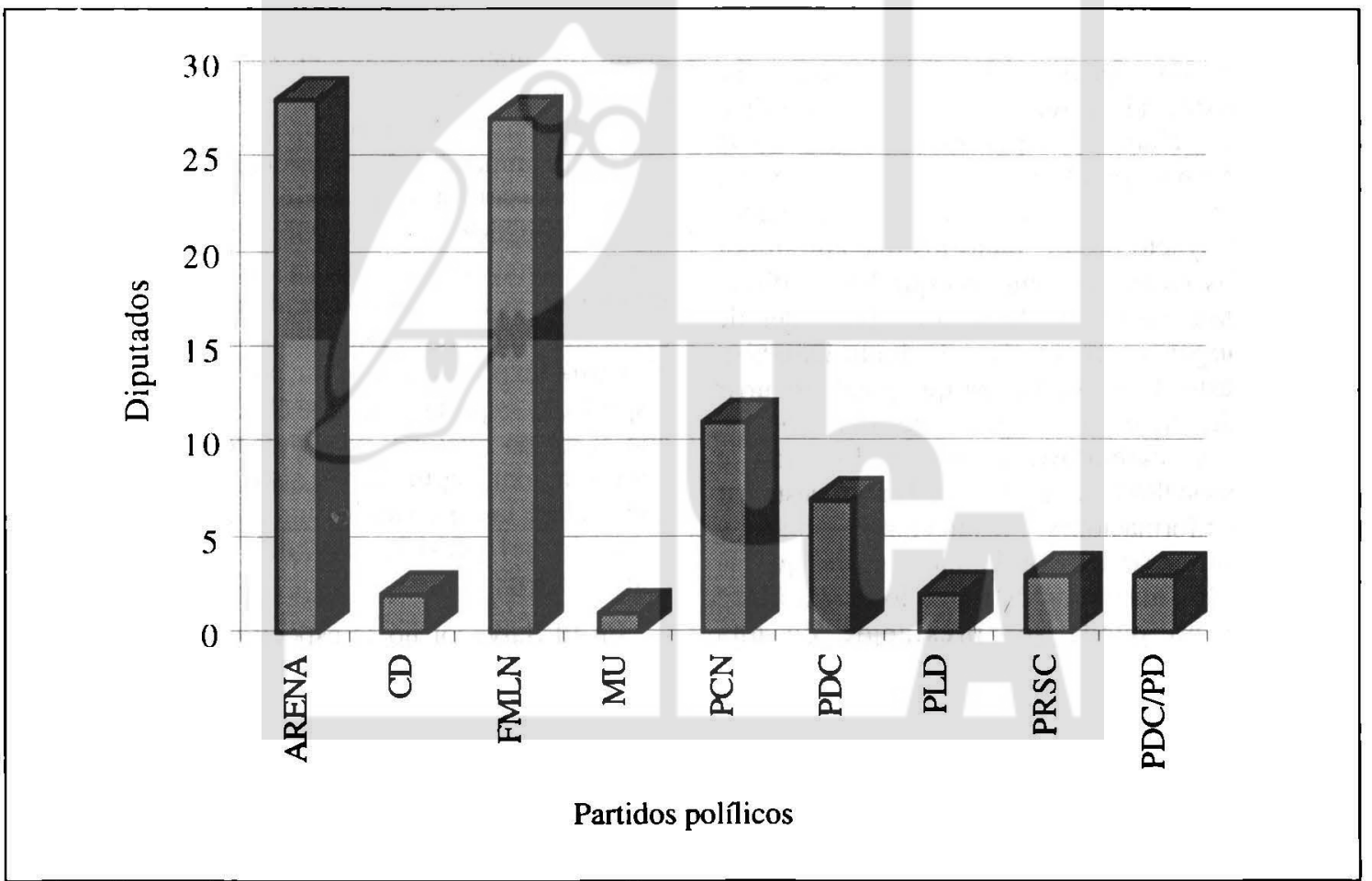

En el pasado, cuando los partidos políticos obtenían la mayoría se convertían en "monarquías

absolutas", denominadas popularmente "aplanadoras". Así, en la historia reciente se pueden 
mencionar las últimas cuatro que han existido desde 1970. Por ejemplo, la aplanadora azul (Partido de Conciliación Nacional), la verde (Partido Demócrata Cristiano), y la azul, blanco y rojo (ARENA). No se puede pasar por alto mencionar que la lectura de la experiencia histórica de estas mayorías ha sido negativa y catastrófica para los intereses de la nación.

\subsection{Funciones de los miembros directivos de las comisiones}

Los miembros directivos de las comisiones tienen funciones específicas con el propósito de hacer eficiente y competente el trabajo de las comisiones y evitar duplicidades en el quehacer de las comisiones legislativas.

Presidente. Las funciones de los presidentes de las comisiones están, por lo general, contempladas en los reglamentos internos de las asambleas. Se pueden mencionar las siguientes: desempeñar el rol de planificador y organizador; dirigir los debates; proponer la agenda; contratar y despedir al personal de apoyo de la comisión; convocar a las sesiones; otorgar la palabra a los diputados en el orden que lo soliciten; conceder permiso a los diputados que por causa justificada se retiren de la sesión; verificar los informes elaborados por el secretario de la comisión; firmar con el secretario las actas; recibir y dar a conocer todos los documentos relacionados con cada proyecto de ley, tanto los que entran por la vía de las plenarias como los que llegan directamente a la comisión, y clasificarlos por orden de llegada o urgencia; presentar a la Junta Directiva el presupuesto de los gastos en que pueda incurrir la comisión en el desempeño de sus labores; organizar y calendarizar las audiencias e interpelaciones; llevar al día los expedientes; gestionar informes o informaciones a instituciones públicas y privadas; nombrar subcomisiones, salvo que la mayoría de los miembros disponga lo contrario. El presidente no puede ser presidente de una subcomisión de la comisión que él presida, etc.

Secretario Las funciones de los secretarios de la comisiones legislativas, a nivel general, son las siguientes: llevar un control y registro sistemático de los dictámenes y piezas de correspondencia que ingresen a la comisión; presentar al plenario informes detallados y periódicos sobre los dictámenes o decisiones que haya tomado la comisión en relación con los diferentes asuntos sometidos a ella; leer los dictámenes en el plenario; levantar actas de las sesiones de la comisión; leer las mismas en cada sesión para que sean aprobadas o modificadas y posteriormente firmadas por él mismo, el presidente y relator de la comisión; asumir la presidencia de la comisión en ausencia del presidente; leer la correspondencia a los demás miembros de la comisión; redactar y leer los dictámenes a los demás miembros de la comisión; elaborar una lista de control de la asistencia y llegadas tardías de los diputados a las sesiones de la comisión para su respeclivo descuento, la cual deberá ser firmada también por el presidente, asimismo, la de los empleados y subalternos de la comisión; firmar las resoluciones de la comisión con antelación para su lectura en el pleno; ser vocero de la comisión; llevar el archivo de la comisión; garantizar la elaboración de la agenda antes de iniciar la sesión de la comisión, etc.

Relator. Las funciones del relator, a nivel general, son las siguientes: dar explicaciones, de igual forma, aclarar cualquier duda o contestar las preguntas que planteen los diputados durante la sesión plenaria o fuera de ella. Por ejemplo, sobre aspectos de forma, contenido, generales o específicos de algún dictamen que haya emitido la comisión, o en relación con cierto expediente que se haya decidido pasar al archivo; relatar, de manera objetiva e imparcial, los diferentes puntos de vista que se viertan en la comisión, relacionados con alguna decisión que se adoptare, tanto por la mayoría como por la minoría que se formen en el interior de la comisión sobre determinado aspecto particular y concreto. Esta situación no impide que el relator exponga aparte su posición personal al respecto, lo importante es que él cumpla a cabalidad con el rol de relator y de diputado miembro de la comisión; dar seguimiento sistemático al trabajo que realiza la comisión; asumir la presidencia en ausencia del presidente y del secretario de la comisión, etc.

En El Salvador no se especifican las funciones de los directivos de las comisiones, lo cual constituye una desorganización y anarquía en el interior de las comisiones. En el Artículo $13 \mathrm{del}$ reglamento interior se encuentra únicamente lo siguiente:

Acordarán las normas internas de su actuación, según sus asuntos, procurando armonizar el estudio detenido con el despacho rápido de los mismos. Con ese fin llevarán un libro de entrada y salida de los expedientes de su conocimiento. 
El secretario o secretaria de cada una de las comisiones, cada tres meses, deberá rendir informe al pleno legislativo, sobre cuantos expedientes tiene la comisión, cuantos ha resuelto durante ese período. Dicho plazo se contará a partir de la vigencia del presente decreto. El referido informe deberá ser claro y sucinto.

Hasta donde se ha investigado, se desconoce si ha existido o existe el manual de normas internas por el cual se rige cada comisión; tampoco se han encontrado los informes trimestrales que supuestamente deben elaborar los secretarios de las comisiones. La pregunta por formularse sería, entonces, ¿qué utilidad o importancia tiene la existencia del actual reglamento interior de la Asamblea Legislativa de El Salvador?

\subsection{Funcionamiento interno de las comisiones}

El funcionamiento intemo de las comisiones está regido, por lo general, en el reglamento interior de cada Asamblea Legislativa. Entre los aspectos más comunes de la práctica parlamentaria internacional se mencionarán a grandes rasgos los siguientes:

Sesiones. Las comisiones se reúnen, por lo menos, dos veces por semana por convocatoria de su presidente, además, una tercera parte de sus miembros puede solicitar al presidente a convocatoria. Las sesiones no se pueden desarrollar paralelamente con la plenaria. El diputado dispone de quince minutos como máximo para exponer, defender o atacar el asunto o cuestión en debate. Por acuerdo de la mayoría se pueden modificar las fechas o aumentar el número de sesiones. Las sesiones son públicas; se elaborará siempre un acta de cada sesión; los diputados formarán parte de la comisión hasta que dure la legislatura, en caso de ser reelegidos no existe impedimento por el cual no puedan continuar en la misma, etc.

En El Salvador, el promedio de duración de una sesión es de tres horas, a excepción de la Comisión Política que es de aproximadamente cuatro horas. Las sesiones se realizan en la quinta planta del edificio legislativo; sólo la Comisión Política sesiona en la octava planta.

Cuadro 8

Sesiones de las comisiones de El Salvador en la legislatura 1997-2000

\begin{tabular}{llr}
\hline \multicolumn{1}{c}{ Comisiones } & \multicolumn{1}{c}{ Días } & Hora \\
\hline Legislación y Puntos Constitucionales* & Lunes y Miércoles & $10: 00$ \\
Relaciones Exteriores e Integración C.A. & Lunes & $9: 00$ \\
Justicia y Derechos Humanos & Martes & $10: 00$ \\
Cultura y Educación & Lunes & $9: 00$ \\
Obras Públicas & Lunes & $10: 00$ \\
Interior y Seguridad Pública & Martes & $10: 00$ \\
Economía y Agricultura* & Martes y Miércoles & $14: 00$ \\
Hacienda y Especial del Presupuesto* & Lunes y Miércoles & $14: 00$ \\
Defensa & Miércoles & $14: 00$ \\
Gracia y Excusas & Martes & $10: 00$ \\
Política* & Miércoles Y Viernes & $3: 00$ \\
Medio Ambiente y Salud Pública & Martes & $9: 00$ \\
La Familia, la Mujer y el Niño & Miércoles & $9: 00$ \\
Trabajo y Previsión Social & Lunes & $1: 00$ \\
\end{tabular}

* Se reúnen por lo menos dos veces a la semana. La hora y el día de la sesión son variables no fijas aunque, por lo general, se sigue el horario establecido aquí.

Archivo. Mantener el archivo de la comisión actualizado para que los diputados, miembros de la misma y de otros, puedan consultarlo. Cada comisión debe presentar sus dictámenes o informes en un plazo de treinta y un días, después de haber recibido la pieza de correspondencia o proyecto de 
ley. En casos especiales, la comisión podrá solicitar prórroga al plenario; si sus miembros irrespetan los períodos, no se les entregará su salario correspondiente, elc.

Quórum. El quórum se establece por lo menos con la presencia de la mitad de los miembros de la comisión; se dan quince minutos de espera para establecerlo, si estos transcurren sin lograrlo, se da por anulada la sesión. A los diputados ausentes se les aplica el respectivo descuento de su salario si no solicitaron permiso justificado con anterioridad. Si en el transcurso de una sesión se pierde el quórum, se levanta la reunión y posteriormente se procede a los descuentos de salarios respectivos de los diputados que abandonaron la sesión, etc.

Votación. Ningún diputado propietario puede delegar su voto, a menos que el suplente presente una autorización oficial debidamente justificada; los acuerdos pueden ser tomados por consenso o por votaciones unánimes o mayoría simple; los dipu- tados que no sean miembros de la comisión pueden participar en la sesión con los mismos derechos que tienen los diputados miembros, a excepción de que no pueden votar; existe libre acceso para el público al registro de votaciones de las comisiones, así como a la lista con los nombres de los diputados que votaron a favor o en contra, los que estuvieron presentes y se abstuvieron de emitir el voto, etc.

El reglamento interior de la Asamblea Legislativa de El Salvador no dice nada acerca del funcionamiento interno de las comisiones. Este es uno de los factores que explican la ineficiencia, tortuguismo, ineptitud y autoritarismo que prevalece en ellas.

\subsection{Las comisiones en El Salvador}

El Salvador dejó de formar parte de las Provincias Unidas de Centroamérica a partir del 18 de febrero de 1841, fecha en que se decretó la Constitución del Estado. Hasta el 13 de agosto de 1886, El Salvador tuvo un Poder Legislativo bicameral.

\section{Cuadro 9 \\ Comisiones del Poder Legislativo bicameral de El Salvador (1849)}

\begin{tabular}{lll}
\hline N & \multicolumn{1}{c}{ Cámara de Diputados } & \multicolumn{1}{c}{ Senado } \\
\hline 1 & De policía interior, Poderes y Excusas & De Policía Interior, de Poderes y Excusas \\
2 & De Legislación y Puntos Constitucionales & De Legislación y Justicia \\
3 & De Relaciones y Crédito Público & De Relaciones y Puntos Constitucionales \\
4 & De Industria, Agricultura y Comercio & De Industria, Agricultura y Comercio \\
5 & De Hacienda y Guerra & De Hacienda, Crédito Público y Guerra \\
6 & De Gracia, Justicia y negocios eclesiásticos & De Instrucción Pública y Premios, de Peticiones \\
& y Redacción de Estilo \\
7 & De Instrucción Pública y Gremios & \\
8 & De Peticiones y Corrección de Estilo & \\
\hline
\end{tabular}

Fuente: datos obtenidos del Reglamento de Diputados y del Reglamento Interior del Senado, ambos del 15 de marzo de 1849.

Las comisiones han "evolucionado" y el reglamento interior también, pero el cambio ha estado determinado por el sistema político antidemocrático y las prácticas de un Poder Legislativo a la vez autoritario y dependiente. Esto explica, en parte, el por qué de la existencia actual de un disfuncional reglamento interior de la Asamblea Legislativa y de la calidad de los actuales diputados. 


\section{Cuadro 10 \\ Evolución de las comisiones legislativas durante 25 años (1919 A 1997)}

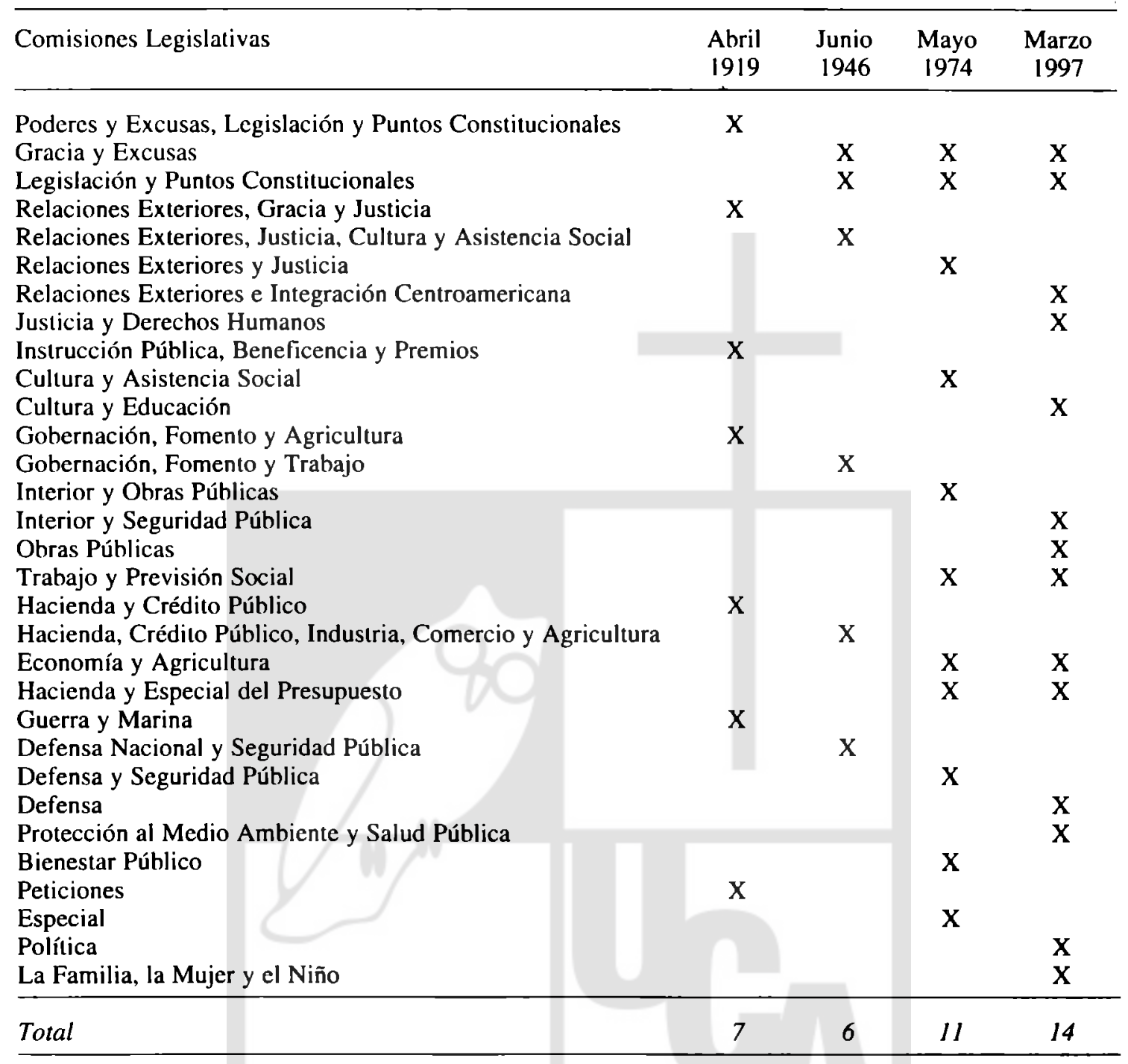

Fuente: Datos obtenidos de los reglamentos interiores de la Asamblea Legislativa de los años correspondientes.

Al iniciarse la legislatura de 1997-2000 se consideró la necesidad de crear las comisiones siguientes: (a) Desarrollo Municipal, para darle un mayor impulso al desarrollo de los 262 municipios del país; hasta la fecha los temas municipales se han abordado en la comisión del interior y de seguridad pública. (b) Técnica para la Modernización Legislativa, que consistiría en convertir el comité técnico en dicha comisión para modificar, entre otros, el reglamento interior de la asamblea y ponerlo a la altura de las necesidades y los nuevos cambios registrados en el país y a nivel internacional. (c) Etica y probidad, para evitar conductas reprochables y garantizar la transparencia en el manejo de los fondos públicos. Por otro lado, también se habló de eliminar la comisión de Gracia 
y Excusa debido a la disminución del trabajo, como consecuencia de los últimos cambios en las barreras arancelarias y el cobro de impuestos.

\section{Funciones de las Comisiones Legislativas en El Salvador}

Las funciones de las comisiones permanentes en El Salvador no se encuentran normadas en el reglamento interior de la Asamblea Legislativa.

\subsection{Funciones de la Comisión Política}

La Comisión Política es la más importante de todas. Aquí es donde verdaderamente se discuten los problemas trascendentales del país. Está integrada por todos los jefes de las fracciones políticas representados en la asamblea y está presidida por el presidente de la Junta Directiva. No hay que olvidar que aquí en El Salvador existen fracciones políticas unipersonales, por lo que si un partido político representado en la asamblea se divide en siete partes y cada una está constituida por un diputado, cada diputado constituye una fracción $y$, por lo tanto, los siete tendrán derecho de formar parte de la comisión política.

Sin embargo, el reglamento interior de la asamblea, al final del Arlículo 12 , se limita a enunciar que "en la $\mathrm{Co}$ misión Política habrá miembros suplentes en el número y proporción que acuerde la misma".

\section{El reglamento interior de la Asamblea Legislativa} de El Salvador no dice nada acerca del funcionamiento interno de las comisiones. Este es uno de los factores que explican la ineficiencia, tortuguismo, ineptitud y autoritarismo que prevalece en ellas.

Que todos los problemas y principalmente los más complicados que pueden dar inconvenicntes, primero los ve la Comisión Política, allí se discuten y se llega a una conclusión y, posteriormente, los pasa al plenario y es este último el que se lleva el crédito ${ }^{18}$.

Mercedes Gloria Salguero Gross, diputada de ARENA (desde 1982 ininterrumpidamente hasta la fecha) y ex presidenta de la Asamblea Legislativa y de la Comisión Política en la legislatura de 19941997, afirmó que en la Comisión Política:

Es donde se llevan todas las cosas realmente conflictivas y difíciles, las que deben tratarse políticamente; hay momentos en que las otras comisiones tienen que resolver sobre esos problemas $y$ hay cosas que definitivamente tienen que ir a la Política. También vemos en la Comisión Política todo aquello que no pueda ser resuelto en otras comisiones y que hacen necesario un cabildeo político para llegar a un acuerdo ${ }^{19}$.

La Asamblea Legislativa sacó a la luz, en 1996, un pequeño folleto publicitario compuesto por generalidades $y$ fotografías de los diputados de la legislatura de 1994-1997, en el cual no aparece el lugar de impresión ni la fecha en que fue elaborado, pero estos

La especialidad de esta comisión es la"todología", no tiene funciones específicas, además, es la comisión que por excelencia trabaja de espaldas al pueblo, pues todas sus sesiones son secretas, es decir, a puerta cerrada, lo cual refleja la falta de transparencia, honestidad, sinceridad y el autoritarismo de los dirigentes y sus respectivos partidos políticos, asimismo es la atmósfera altamente contaminada que caracteriza a la Asamblea Legislativa de El Salvador. olvidos o ignorancia no son extraños en la asamblea. En el folleto se encuentran las funciones de las 14 comisiones, y sobre la Comisión Política explica que:

En esta Comisión se estudian los asuntos que por su complejidad requieren un tratamiento al más alto nivel político parlamentario, procurando lograr el consenso y la unanimidad en las resoluciones propuestas al Pleno.

En consecuencia, le corresponde dictaminar

18. Entrevista a Miguel Angel Saénz Varela, diputado del FMLN, Secretario del Comité Técnico, realizada el 21 de octubre de 1996, en el local de la fracción del FMLN.

19. Entrevista a Mercedes Gloria Salguero Gross, diputada de ARENA, Presidenta de la Asamblea Legislativa y de la Comisión Política, el 24 de octubre de 1996, en la Asamblea Legislativa. 
sobre los más variados aspectos de la vida política e institucional del Estado; y, además, sobre la elección de importantes funcionarios públicos ${ }^{20}$.

Sin ánimo de parecer simplistas, se diría que la Asamblea Legislativa de El Salvador puede sintetizarse en la Comisión Política. La Junta Directiva, las comisiones legislativas permanentes y el plenario son la justificación de la existencia de un Poder Legislativo que no legisla de acuerdo con la doctrina ni con el derecho parlamentario, dicho Poder sirve de justificación para saciar los apetitos voraces de los dirigentes políticos, de la oligarquía, de las multinacionales y los militares.

\subsection{Funciones de la Comisión de Legislación y Puntos Constitucionales}

Después de la Comisión Política, la Comisión de Legislación y Puntos Constitucionales es la segunda en importancia. No obstante, en la legislatura de 1994-1997, ARENA decidió nombrar como presidente de esta comisión al diputado Walter Araujo, quien es un bachiller egresado de la carrera de derecho, que se ha caracterizado en la asamblea por su prepotencia y su vocabulario vulgar y soez, aparte de que su prestigio rodó por los suelos después de haber sido demandado por no cumplir con sus obligaciones paternales.

Esta comisión prácticamente imposibilitaba legislar a las demás comisiones, puesto que era el "colador" de los proyeclos de ley; sin embargo, con la presencia del FMLN a partir de la legislatura de 1994-1997, esta situación cambió un tanto, ya que con la pérdida de la mayoría de diputados por ARENA, en las elecciones de 1997, este partido no pudo continuar con su práctica. Por ejemplo, cuando un proyecto de ley ingresaba a la comisión de educación, después de haber sido aprobado por ésta se enviaba a la comisión de legislación y puntos constitucionales para una supuesta revisión "técnico jurídica", que no era más que la justificación para una revisión de carácter político $\mathrm{y}$, hasta que esta comisión no le daba el visto bueno, no podía ser enviada al pleno. Ahora, después de que un proyecto de ley cuenta con el dictamen de una comisión, pasa directamente al plenario.

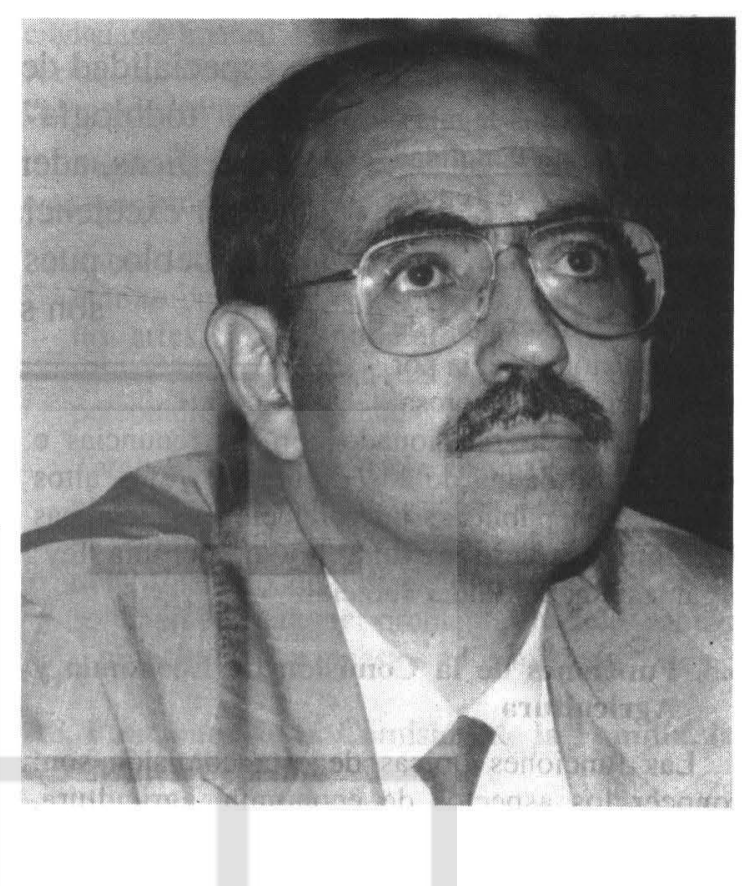

Según el folleto Nuestra Asamblea Legislativa, el trabajo de esta comisión es la siguiente:

En esta Comisión se estudia y aprueba un importante número de proyectos de ley y de reformas, se estudia y dictamina sobre vetos, observaciones presidenciales, antejuicios, interpela-ciones e inconstitucionalidades; es decir, todo lo relacionado con los controles interestatales que contempla la Constitución de la República ${ }^{21}$.

Otra de las funciones que tiene, según el Artículo 16 del reglamento interior de la asamblea, consiste en que:

Inmediatamente después de que se practique la elección de un funcionario por parte de la Asamblea, está obligada a iniciar y seguir diligencias a fin de comprobar, por cualquier medio legal, si las personas electas reúnen los requisitos establecidos por la Constitución, de lo cual dará cuenta documentada y razonada a la Asamblea, a más tardar treinta días después de verificada la elección.

20. Asamblea Legislativa. Nuestra Asamblea Legislativa 1994-J997, S.l.i., S.ed., S.f., p. 23.

21. Ibid., p. 22. 
En caso de que una elección recaiga en persona que no reúna los requisitos legales, se declarará la nulidad existente y se repondrá inmediatamente la elección.

En las funciones de esta comisión de deja por fuera, de manera expresa, lo siguiente: lo relacionado con las renuncias e incompatibilidades de los diputados y los altos funcionarios públicos; interpretaciones auténticas de algún artículo de una ley o, de una ley; organización del Poder Judicial.

\subsection{Funciones de la Comisión de Economía y Agricultura}

Las funciones típicas de esta comisión son: conocer los aspectos de economía, agricultura, ganadería, comercio, industria, tecnología, energía, recursos naturales, turismo, pesca, alimentación y materias afines.

Según el folleto Nuestra Asamblea Legislativa, las temáticas de esta comisión son:

Los asuntos macro y micro económicos, tales como aranceles a las importaciones, aforos, canasta básica y comercio en general; incluyendo los aspectos agrícolas de la economía nacional. Dictamina sobre incentivos y proyectos de desarrollo ganadero, cafetalero o cañero; también le corresponden los asuntos relacionados con la industria y la banca, especialmente sus políticas crediticias ${ }^{22}$.

\subsection{Funciones de la Comisión de Hacienda y Especial del Presupuesto}

A nivel teórico, a esta comisión le corresponde el estudio, el análisis y la aprobación del presupuesto de la nación, así como dar seguimiento, supervisar y evaluar los aspectos siguientes: la liquidación del presupuesto general de la nación; el informe anual de la Corte de Cuentas de la República y de los asuntos de Hacienda. Asimismo, el presupuesto general de la nación, créditos o empréstitos que suscriba el Ejecutivo; la política salarial, fiscal $y$ monetaria del país; tarifas de servicios que presta el Estado.

Según el folleto Nuestra Asamblea Legislativa:

Esta Comisión realiza cada año la importante tarea de estudiar y aprobar la Ley General del Presupuesto, la Ley de Salarios y las reformas de las mismas.

Además, se encarga de dictaminar sobre autorizaciones al Organo Ejecutivo para negociar con organismos financieros internacionales la contratación de préstamos y aprobarlos posteriormente. En general, decide todo lo relativo a la Hacienda Pública y financiera del país ${ }^{23}$.

\subsection{Funciones de la Comisión de Relaciones Exteriores e Integración Centroamericana}

Se supone que las funciones de esta comisión son conocer los asuntos relacionados con organizaciones regionales e internacionales vinculadas con la Asamblea Legislativa; el Sistema de Integración Centroamericana; la organización y selección del personal diplomático y consular, convenios, tratados, convenciones, pactos, protocolos, contratos internacionales y materias afines.

Según el folleto Nuestra Asamblea Legislativa, esta comisión:

Se especializa en estudiar y dictaminar sobre Tratados, Convenios, Protocolos, Enmiendas y todo tipo de acuerdos de carácter internacional, a efecto de que la Asamblea pueda ratificarlos o no, con lo que se determina su incorporación en la legislación nacional, y que -a su vezdeben prevalecer sobre todas las leyes secundarias del país.

Esta Comisión también se encarga de otorgar los permisos que señala la Constitución del país, para que los salvadoreños puedan aceptar las distinciones honoríficas otorgadas por gobiernos

22. Ibid., p. 21.

23. Ibid. 
extranjeros; dictamina sobre el tránsito de tropas extranjeras en el territorio nacional; y en general, sobre todos los aspectos que implica la integración centroamericana ${ }^{24}$.

\subsection{Funciones de la Comisión de Justicia y De- rechos Humanos}

Esta comisión se encarga de abordar todos los aspectos relacionados con los derechos humanos y la justicia. Según el folleto Nuestra Asamblea Legislativa:

En esta Comisión los Diputados trabajan con miras a la solución del complejo problema de la administración de justicia, incluida la situación carcelaria del país. Esta especialización incluye la modernización del Registro de Propiedades y particularmente las denuncias y expectativas públicas sobre violaciones a los derechos fundamentales. A esta Comisión le corresponde -entonces - el estudio de la legislación relacionada con el Organo Judicial, el Ministerio Público y los Derechos Humanos ${ }^{25}$

Esta comisión debería redactar un Código de Etica Parlamentaria, el cual, después de haber sido aprobado en plenaria, debería cumplirse con fidelidad por parte de todos los diputados bajo la supervisión de la misma comisión.

\subsection{Funciones de la Comisión de Cultura y Educación}

Las funciones de esta comisión deberían ser, entre otras, las siguientes: seleccionar y modernizar la adquisición de libros, documentos y otros materiales y recursos necesarios para el continuo mejoramiento de la biblioteca de la asamblea; fomentar la cultura, la educación y los deportes. Asimismo, contribuir al rescate y la rehabilitación de las raíces históricas nacionales; promocionar y desarrollar los valores nacionales; proporcionar las condiciones para implementar actividades artísticas y literarias; preservar y estimular las obras y personalidades en vida o postmorten - que hayan dado un significativo aporte a la cultura, ciencia y tecnología, y que sean decla-

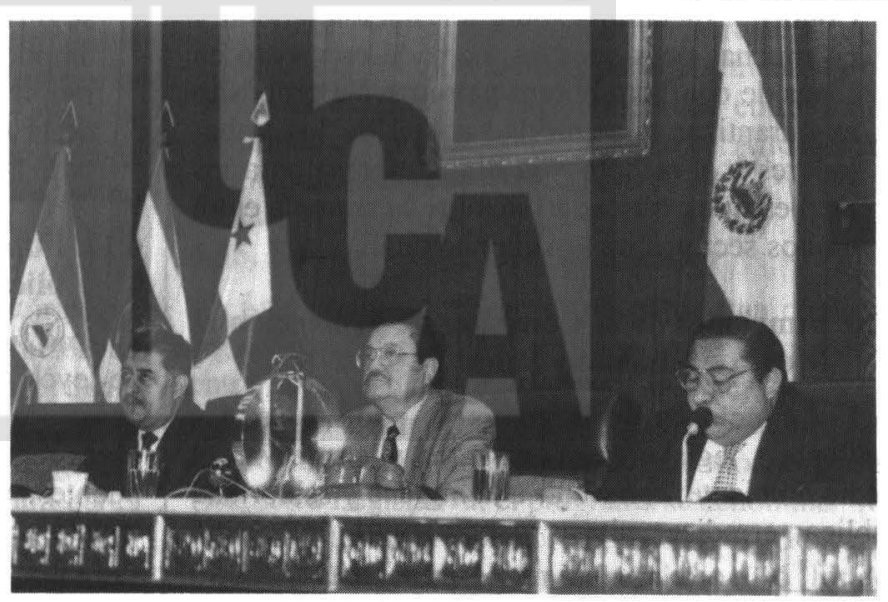

rados patrimonio de la nación y se les conceda ciudadanía honorífica y/o pensión vitalicia. De igual forma, abordar las áreas de comunicaciones y comunidades indígenas.

Según el folleto Nuestra Asamblea Legislativa, esta comisión:

Estudia todos los proyectos relacionados con el ámbito cultural y educativo del país, es decir, las artes, los monumentos nacionales y los títulos honoríficos que la Asamblea confiere a personalidades destacadas en esta materia.

También tiene a su cargo los asuntos relativos al sistema educativo nacional, particularmente el seguimiento en la ejecución de las políticas del Ministerio de Educación, mediando en la solución de cualquier problema en dicho campo o proponiendo respuestas a los mismos ${ }^{26}$.

\subsection{Funciones de la Comisión de la Familia, la Mujer y el Niño}

Las funciones de esta comisión podrían ser las siguientes: contribuir a la elaboración y al real cumplimiento de una legislación que proteja y defienda a la familia, la mujer y el niño; crear instituciones públicas y colaborar con los Organismos No Gubernamentales que protegen, defienden y ayudan a la familia, las mujeres, las personas de la tercera edad y los niños desnutridos, abandonados, maltratados, abusados física y/o sexualmente; crear leyes de discriminación positiva en favor de la mujer para garantizar su inserción

24. Ibid., pp. 23-24.

25. Ibid., p. 22.

26. Ibid., p. 20. 
en el sistema productivo; la participación política, cultural y social.

Según el folleto Nuestra Asamblea Legislativa, la temática de esta comisión es:

La preservación del núcleo familiar como base de la sociedad y la solución de los problemas que más le afectan. En tal sentido, se ocupa de dictaminar sobre aspectos legales relacionados con la prevención del tráfico ilegal de menores, del aborto y del abuso físico y moral contra la mujer; con énfasis particular en la protección de los derechos del niño ${ }^{27}$.

\subsection{Funciones de la Comisión del Trabajo y Previsión Social}

Las funciones de esta comisión podrían ser las siguientes: bienestar social, protección social, servicios sociales y comunitarios, mano de obra, condiciones sociales del trabajo tanto del hombre como de la mujer, seguro de desempleo, protección de la vejez, jubilaciones, pensiones, asignaciones y beneficios familiares; abordar la problemática de los sindicatos, gremios y asociaciones de empleados y/o trabajadores, lo relacionado con la legislación laboral nacional e internacional; servir de mediador en los conflictos de los obreros con los sectores patronales, tanto de las instituciones públicas como de las privadas.

Según el folleto Nuestra Asamblea Legislativa, esta comisión:

Conoce y dictamina sobre legislación laboral y en muchas ocasiones ha mediado con éxito en casos de conflicto obrero patronal. Su propósito es garantizar la seguridad social de los trabajadores y el respeto a la libre empresa para los empleadores; buscando siempre la armonía entre ambos sectores de la vida nacional ${ }^{28}$.

\subsection{Funciones de la Comisión de Protección al Medio Ambiente y Salud Pública}

Las funciones de la comisión podrían ser las siguientes: legislar para proteger y conservar el medio ambiente; contribuir a la higiene y salubridad pública; erradicar plagas y epidemias; injerencia en la organización y el funcionamiento de la salud pública, los vicios sociales y la profilaxia de enfermedades sociales.

Según el folleto Nuestra Asamblea Legislativa esta comisión:

Dictamina sobre aspectos legales para la protección, conservación, restauración, desarrollo y aprovechamiento de los recursos naturales; además de todo lo concerniente a la prevención y control de las enfermedades, para la protección de la salud pública.

Todo esto incluye la aprobación de medidas de control ético y técnico para conservar la salud de todo el pueblo, la vigilancia en la implementación de las políticas de seguridad social y ambiental, lo mismo que en las actividades ejecutivas del Ministerio de Salud Pública y Asistencia Social ${ }^{29}$.

\subsection{Funciones de la Comisión del Interior y Seguridad Pública}

Las funciones de la Comisión del Interior y Seguridad Pública son las siguientes: contribuir al desarrollo de los municipios y atender asuntos relacionados con las municipalidades y seguridad pública.

Según el folleto Nuestra Asamblea Legislativa, a la comisión:

Se le encomiendan los asuntos municipales y todo lo relacionado con los problemas de la seguridad ciudadana, en los términos más amplios. Dictaminan sobre impuestos o arbitrios municipales, e igualmente sobre las actividades de la Academia Nacional de Seguridad Pública o de la Policía Nacional Civil ${ }^{\text {?n). }}$.

\subsection{Funciones de la Comisión de Obras Pú- blicas}

Las funciones podrían centrarse en la emisión de leyes sobre el planeamiento, autorización de la construcción, apertura, mejoras y conservación de obras públicas, tales como, carreteras, vías férreas, puentes, muelles, aeropuertos, etc., y fomentar la construcción de viviendas económicas.

27. Ibid., p. 22.

28. Ibid., p. 24.

29. Ibid., p. 23.

30. Ibid., p. 21. 
Según el folleto Nuestra Asamblea Legislativa, esta comisión se encarga de:

Rcalizar las gestiones correspondientes para posibilitar la distribución de agua potable o encrgía eléctrica en las comunidades que lo requieren; y además todo lo concerniente a proyectos de vivienda popular y servicios de telecomunicaciones; también supervisa el programa de acción ejecutiva que realiza el Ministerio de Obras Públicas, en lo referente a la construcción y reparación de carreteras y caminos del territorio nacional ${ }^{3 !}$.

\subsection{Funciones de la Comisión de Gracias y Excusas}

Las funciones de esta comisión son mínimas porque el trabajo es, por lo general, intranscendente, por tal motivo sería mejor que desapareciera y que las labores que realiza se distribuyeran en otras comisiones.

Según el folleto Nuestra Asamblea Legislativa, a esta comisión le corresponde:

Dictaminar sobre todas las solicitudes de exención de impuestos presentadas por las instituciones de carácter benéfico que lo requieran. También le compete dictaminar sobre las peticiones de indulto para los reos condenados, previo informe de la Corte Suprema de Justicia ${ }^{32}$.

\subsection{Funciones de la Comisión de Defensa}

Esta es la comisión más innecesaria de la Asamblea Legislativa, pero antes de desaparecer su función fundamental y última debería ser preparar un proyecto de ley para eliminar a la Fuerza Armada "Salvadoreña" y declarar al Estado salvadoreño neutral y desarmado, porque la sola existencia de la institución militar constituye un peligro para la seguridad nacional. Además, a nivel histórico se puede afirmar que ha sido una fuerza armada de ocupación nacional que sólo ha servido para cometer crímenes y delitos de lesa humanidad contra el pueblo salvadoreño, $y$ ha defendido a sangre y fuego los intereses de la oligarquía "nacional"; por otra parte, consume un presupuesto constituido por una cantidad enorme de millones de colones que podrían invertirse

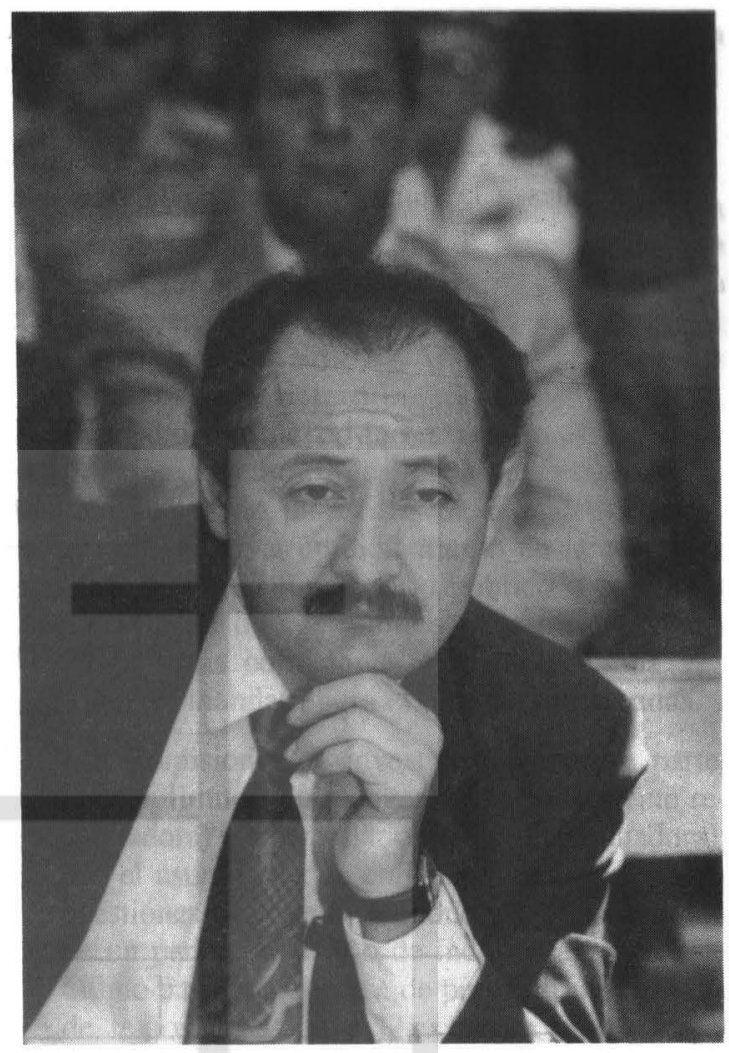

en beneficio de la población y no en su contra, como lo es actualmente.

Según el folleto de Nuestra Asamblea Legislativa, esta comisión se encarga de:

Estudiar y dictaminar todo lo referente a legislación o doctrina militar, particularmente se encarga de propiciar las relaciones entre fuerza armada y población civil, o entre Alto Mando Militar y Organo Legislativo ${ }^{33}$.

\subsection{Funciones del Comité Técnico}

Este comité no tiene el rango de una comisión legislativa. Su creación es producto de un convenio entre la Asamblea Legislativa y la Agencia para el Desarrollo Internacional (USAID), el cual consistía en donar fondos económicos para modernizar la Asamblea Legislativa; el programa se denominó "fortalecimiento de la Asamblea Legislativa". Posteriormente, este comité también administró fondos

31. Ibid., p. 22.

32. Ibid., p. 21 .

33. Ibid., p. 20. 
donados por el Programa de las Naciones Unidas Para el Desarrollo (PNUD) para la modernización de la asamblea.

El Comité Técnico analiza y decide, esa decisión pasa después a la Junta Directiva de la Asamblea
Legislativa, entidad que es la que en definitiva decide. Con la Comisión Política, el Comité Técnico no tiene ninguna relación. Un diputado funge como coordinador del Comité y es quien realiza el enlace entre la Junta Directiva y el Comité Técnico.

\section{Gráfica 3 \\ Organigrama}

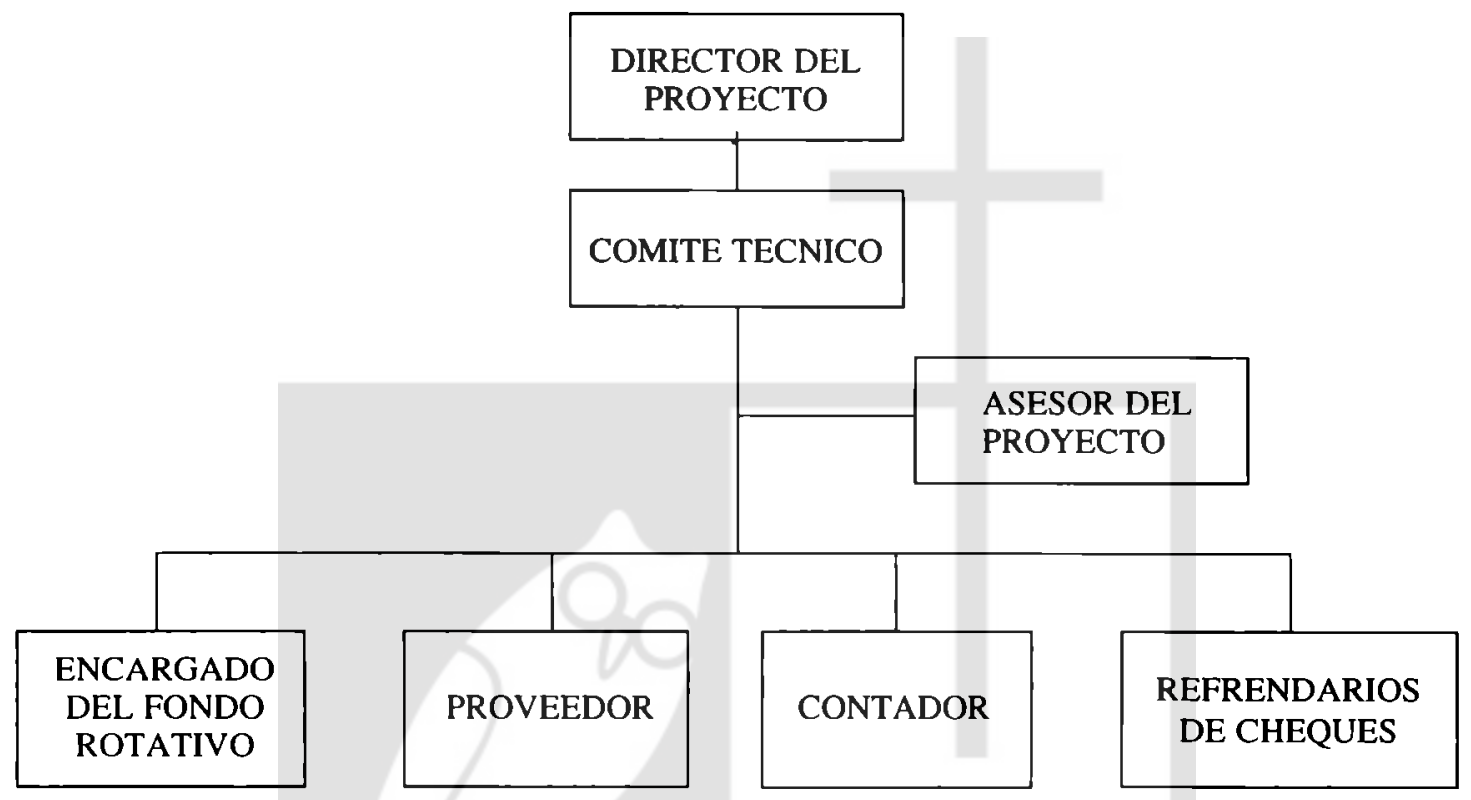

Este comité es un organismo eminentemente técnico y está constituido por un diputado de cada fracción política para administrar la inversión de los fondos y desarrollar proyectos en tres áreas:

A. Mejorar y construir infraestructura. Se construyó el edificio anexo que es el administrativo y se remodelaron ocho pisos del edificio de la asamblea.

B. Abastecer con equipo de oficina, por ejemplo, faxes, teléfonos, escritorios, computadoras, así como capacitaciones de personal en los nuevos softwares.

C. Atender al público, para ello fue necesario brindar capacitaciones al personal técnico, administrativo y a los diputados.

Sería bueno que esta comisión se convirtiera en una comisión permanente de la asamblea, encargada de promover la modernización y democratización de la misma, igualmente, que se ocupe del estudio, actualización y modernización continua del reglamento interior de la asamblea para adecuarlo a la altura de las necesidades y los nuevos cambios que se registran en el país y a nivel internacional.

\subsection{Subcomisiones legislativas}

Las subcomisiones se forman en el interior de las comisiones permanentes, a petición del presidente de la comisión o por iniciativa de cualquier diputado, siempre y cuando en ambos casos cuenten con el respaldo de la mayoría de la comisión. Las subcomisiones conservan independencia en su respectivo rol en relación con la comisión de donde se formaron. Uno de los objetivos de las subcomisiones es lograr flexibilidad, agilidad, 
eficiencia y descentralización de las responsabilidades; de igual forma, la cualificación en la especialización del trabajo legislativo. En la mayoría de las Asambleas Legislativas se liene cada vez más un número creciente de subcomisiones; esta situación permite concluir a Claire-Emmanuelle Longuet que "las Asambleas Legislativas del fin del siglo XX son de las subcomisiones"?.14.

El funcionamiento interno de las subcomisiones es prácticamente el mismo que rige a las comisiones permanentes. En cuanto a su composición, por lo general están constituidas por un número reducido de diputados más especializados, más conocedores o más interesados en la problemática u objeto de trabajo; el promedio de miembros es de tres a cuatro diputados. Por lo general, se trata de mantener la representatividad de las fracciones políticas que existe en el seno de la Asamblea Legislativa. Claro está que la composición depende del número de diputados que forman cada comisión y del asunto por tratar. El número exiguo de diputados les permite tener facilidad en la planificación del trabajo, ponerse de acuerdo en el menor tiempo, dividirse las tareas, realizar un trabajo más personalizado, lo cual implica mayor responsabilidad que la que cada uno tiene en las comisiones permanentes, etc.

\subsection{Las subcomisiones y la investigación}

El surgimiento de las subcomisiones también está íntimamente relacionado con la investigación. La experiencia histórica del trabajo de las subcomisiones ha dado resultados positivos, por lo que cada vez se observa que su existencia es necesaria y hasta indispensable para abordar casos concretos y específicos que necesitan profundizarse, además de agilizar los resultados de la labor legislativa, sin menoscabo de disminuir la calidad y eficiencia que, por lo general, ha caracterizado los informes finales de las subcomisiones.

En las subcomisiones hay algunas limitantes. Por ejemplo, el presidente de la comisión permanente no puede ser simultáneamente el presidente de la subcomisión que se haya formado en el interior de la comisión que él preside. Ningún diputado puede ser más de una vez presidente de una subco- misión, ni ser miembro de más de una subcomisión de la misma comisión permanente.

\subsection{Las Comisiones de Investigación}

Estas comisiones también son conocidas con los nombres de especiales, extraordinarias, de encuestas, ad hoc o select committees. La mayoría de las veces, éstas surgen específicamente para realizar o verificar investigaciones sobre aspectos o mandatos que determine el pleno. Además, pueden abordar actividades administrativas y privadas, por ejemplo, gestión financiera, técnica, política, así como para fines de iniciativa de ley, reforma legislativa, enjuiciamiento de la conducta personal de algún funcionario público o cualquier otro asunto de interés público y de trascendencia nacional. Estas comisiones se disuelven una vez cumplido el mandato para el cual fueron creadas.

Las Comisiones de investigación, por su parte, pueden limitarse a recoger dalos (meramente recopiladora) o a formular opinión (dictaminadora); por el asunto en que entienden pueden ser para cuestiones personales (conducta y honorabilidad de un parlamentario) o de índole real, y en este último caso preocuparse de preparar una reforma de textos (legislativas), examinar cómo se ha desenvuelto el sufragio (electorales), enjuiciar la conducta del Gobierno en una materia (políticas), o averiguar cómo se desenvuelve un servicio público (administrativas); finalmente, pueden ser de una sola Cámara o formarse con miembros de ambas (Comisiones mixtas) ${ }^{35}$.

Las comisiones de investigación surgen, además, para garantizar la función primordial y esencial que debe cumplir la Asamblea Legislativa, como es el control que debe ejercer sobre los Poderes Ejecutivo y Judicial.

Por otra parte, es necesario mencionar que también pueden formarse subcomisiones en el interior de las comisiones de investigación, "siempre que ello no implique una delegación de autoridad". Estas no pueden informar directamente a la Cámara, deben hacerlo a través de la Comisión de la que forman parte ${ }^{36}$.

34. Claire-Emmanuelle Longuet. Le Congrès des Etats-Unis, Que sais-je?, París, Presses Universitaires de France, 1989, p. 78.

35. Pérez Serrano, Nicolás. Tratado de Derecho Político, Madrid, Civitas, Segunda Edición, 1984, p. 813.

36. Santaolalla, Fernando. El Parlamento y sus instrumentos de información (preguntas, interpelaciones y comisiones de investigación), S.l.i., Editorial Revista de Derecho Privado y de Derecho Reunidas, S.f., p. 167. 


\subsubsection{Los miembros de las Comisiones de In- vestigación}

Las composición de los miembros es democrática y reflcja la composición política que prevalece en la Asamblea Legislativa, es decir, son representativas y guardan el equilibrio político. Los diputados pueden formar parte sólo de una comisión de investigación. El pleno es el que a través de la elección decide quienes serán sus miembros y su mandato.

Las membresías de las comisiones de investigación pueden estar constituidas por diputados y particulares, en calidad de especialistas para brindar asesoría, quienes pueden participar en las sesiones de audiencia y deliberaciones internas; estos tienen voz pero no voto. Por tal razón, se les conoce con el nombre de comisiones de investigaciones mixtas o semiparlamentarias.

El funcionamiento de las comisiones de investigación, por lo general, se encuentra normado en el reglamento interno de las Asambleas Legislativas. A grandes rasgos, se pueden mencionar los aspectos siguientes, por ejemplo, en lo que respecta al quórum, éste lo forman, por lo menos, la mitad de los diputados que la integran. Las comisiones establecen la planificación del trabajo y la calendarización de sesiones. Estas no deben llevarse a cabo paralelamente a las del plenario o a las de otras comisiones, sin embargo, no es un impedimento para que la comisión realice sesiones en países extranjeros, siempre y cuando la siluación lo amerite, pero para ello debe contar con la autorización del pleno.

Las sesiones de las comisiones de investigación en Gran Brelaña, y por lo general en muchas Asambleas Legislativas de países democráticos, no son totalmente cerradas; en Gran Bretaña, por ejemplo:

Respecto al carácter público o reservado de las sesiones celebradas por los órganos aquí estudiados, debe decirse que éstos, salvo que la Cámara disponga otra cosa, pueden acordar que las declaraciones de testigos tengan lugar en sesiones públicas, lo que en la práctica constituye la regla general ${ }^{37}$. En cambio, las sesiones destinadas a deliberaciones entre los componen- tes de las Comisiones tienen lugar invariablemente a puerta cerrada. Los diputados de la Cámara de los Comunes pueden estar presentes en cualquier reunión de los Select Committees, pero es de estricta cortesía retirarse cuando sean invitados a ello por las Comisiones que deseen celebrar sus sesiones con sólo sus micmbros ${ }^{3 \mathrm{x}}$.

En El Salvador, según la Constitución Política, en el Ordinal $320 \mathrm{del}$ Artículo 131, corresponde a la Asamblea Legislativa:

Nombrar comisiones especiales para la investigación de asuntos de interés nacional y adoptar los acuerdos o recomendaciones que estime necesarios, con base en el informe de dichas comisiones.

En el Artículo 52, del reglamento interior de la Asamblea Legislativa, se "especifica" el mandato constitucional:

La Asamblea nombrará las comisiones especiales a que se refiere el Ordinal 320 del Art. 13I, de la Constitución, con el número de diputados o diputadas que estime conveniente.

Las comisiones especiales así constituidas elegirán un presidente o presidenta, un relator o relatora y un secretario o secretaria, teniendo los demás miembros la calidad de vocales.

\subsubsection{Condiciones y apoyo a las Comisiones de Investigación}

Las comisiones de investigación necesitan condiciones propicias, favorables e idóneas para cumplir el objetivo para el cual fueron creadas, es decir, condiciones especiales porque de lo contrario se crearán con el propósito de distraer la atención de la población y, en este sentido, colocarían una cortina de humo sobre un problema fundamental de la nación, encubrirían la corrupción, etc. Las comisiones al no contar con las condiciones que garanticen la profundización de la investigación, sólo serán un pretexto más para argumentar que existe democracia cuando en el fondo lo que hay es autoritarismo y corrupción.

La investigación siempre ha sido una técnica vital en el sistema parlamentario. Investigar significa realizar indagaciones, pesquisas $y$

37. Los Select Committees que celebran todas sus sesiones a puerta cerrada constituyen una minora. Vid. Partington, M. "Parliamentary Committees: recent developments" en Parliamentary Affairs, 1969-1970, p. 31.

38. Santaolalla, Fernando, Op. cit., pp. 166 y 167. 
recopilación de noticias sobre hechos u objetos, sea por medio de personas expertas, sea por inspecciones oculares, sea mediante examen de documentos o interrogatorios de individuos. Las investigaciones parlamentarias son generalmente admitidas, casi sin excepción. Y admitidas con alcance muy amplio, que abarca todo el funcionamiento del Estado ${ }^{39}$.

En países con sistemas políticos excluyentes y discriminadores se crean comisiones de investigación no para investigar sino para evitar que se encuentre la verdad, por lo que la característica principal es la falta de condiciones especiales para realizar la investigación, por lo tanto, prevalecen obstáculos y sabotajes al trabajo mínimo y superficial que podrían realizar.

Las condiciones, los recursos y las facilidades constitucionales con las que cuentan las comisiones de investigación se encuentran estipuladas también en los reglamentos interiores de las Asambleas Legislativas.
Los tres Poderes del Estado históricamente han sido utilizados, así como también los militares, por la oligarquía como fuente de enriquecimiento ilícito e instrumentos para mantener en la miseria, el analfabetismo, el desempleo, la represión y explotación, entre otros, a la población de Cuscatlán. y estudios con los mismos poderes y las mismas limitaciones que la autoridad judicial" ${ }^{\text {(1) }}$.

En este mismo orden, las comisiones de investigación pueden remitir a los tribunales o al plenario, para formación de antejuicio, según sea el caso, a las personas que hayan delinquido durante el proceso de audiencia. Por ejemplo, por haber ocultado o tergiversado información - perjurioo no presentar o alterar la documentación requerida; ausencia a una citación hecha por la comisión desacato-, en este caso, se puede hacer comparecer a la persona con el auxilio de la fuerza pública; influencia o interferencia ejercida por algún miembro del Ejecutivo; conducta dolosa; soborno de testigos; negarse a prestar juramento o a declarar, etc.

En El Salvador, las condiciones y los recursos de que disponen las comisiones de investigación se encuentran únicamente en tres artículos que son el Artículo 132 de la Constitución y los Artículos 53 y 54 del reglamento interior de la Asamblea Legislativa. A manera de ejemplo se pueden mencionar las siguientes: contratar servicios de inteligencia; permitir libre acceso a todas las dependencias oficiales y a los recintos, domicilios y documentos privados - con orden de allanamiento emitida por un juez-; hacer comparecer ante sí a cualquier persona, sea alto funcionario público o particular; tener acceso a expedientes judiciales, sin menoscabo de la independencia del Poder Judicial; conocer los secretos profesionales, industriales, fiscales y de la defensa nacional; declaraciones de renta y cuentas bancarias - aquí impera el principio del primado del interés de la nación sobre cualquier interés particular-, etc.

En Italia, según el Artículo 141, numeral 2, del reglamento de la Cámara de los Diputados, a las comisiones de investigación les corresponde que: "la Comisión de encuesta procede a la indagación
Estos son tan amplios que prácticamente la profundidad, eficiencia y eficacia de las comisiones de investigación se pierden.

Art. 132. Todos los funcionarios y empleados públicos, incluyendo los de Instituciones Oficiales Autónomas y los miembros de la Fuerza Armada, están en la obligación de colaborar con las Comisiones Especiales de la Asamblea Legislativa; y la comparecencia y declaración de aquellos así como las de cualquier otra persona, requeridas por las mencionadas comisiones, serán obligatorias bajo los mismos apercibimientos que se observan en el procedimiento judicial.

Art.53. Las comisiones especiales desarrollarán su trabajo de investigación de los asuntos específicos que les hayan sido encomendados, con toda la amplitud que para ello se requiera.

39. Bidart Campos, German J. Tratado elemental de derecho constitucional argentino, Buenos Aires, EDIAR, Tomo II, 1988, p. 105.

40. Santaolalla, Fernando. Op. cit., p. 195. 
Art.54. Para que estas comisiones puedan realizar sus investigaciones, con la eficacia y diligencia que el asunto a tratar demande, los funcionarios y empleados públicos en general, así como los miembros de la Fuerza Armada y cualquier otra persona, deberán colaborar con las mismas asistiendo a las citas que se les hicieren o proporcionando por escrito cualquier información que se les solicitare, tal y como lo dispone el Art. 132 de la Constitución.

\subsubsection{Informe final de las Comisiones de In- vestigación}

Según la práctica legislativa, a nivel mundial, cuando la Asamblea Legislativa acuerda la creación de la comisión, al mismo tiempo determina el plazo en que deberá trabajar y la fecha en que presentará el informe, y con la presentación de éste al plenario -para su respectiva modificación, aprobación o rechazo-, la comisión de investigación se disuelve. La asamblea puede, en caso de estimarlo necesario, dar prórroga al trabajo de la comisión. Si en el informe se contemplan elementos para la formación de causa, éste será enviado y puesto a la orden del poder judicial para que este Organo del Estado determine el juzgamiento de aquellas personas que hayan transgredido el ordenamiento jurídico interno del país.

Es importante señalar, también, que una comisión investigadora nace con un fin o fines claramente determinados en la moción que le da origen. Sin embargo, sus resultados pueden servir para diversos propósitos, que van más allá de la función contralora propiamente dicha. Pueden dar lugar a una nueva legislación, a la creación de organismo, la rectificación de políticas, la anulación de contratos administrativos, el mejoramiento de los sistemas administrativos y la renuncia de funcionarios públicos, para citar sólo algunos ejemplos ${ }^{4 !}$.

El informe contiene, entre otros elementos, una exposición de propósitos, conclusiones y recomendaciones; puede estar constituido por dos partes: una por la mayoría y otra por la minoría; puede contener breves resúmenes de testimonios y declaraciones obtenidas, y la propuesta de un proyecto de ley que considere pertinente como resultado de la investigación. Los informes se hacen del conocimiento público y se editan en el Diario Oficial. El informe no tiene un carácter vinculante, es decir, no tiene efectos jurídicos, sino que es de propuestas, exhortaciones, recomendaciones o sugerencias, en otras palabras, no obliga al Poder Judicial, al Ejecutivo ni al mismo Legislativo a tomar literalmente las resoluciones dictadas en el informe, pero esto no significa literalmente que los Poderes aludidos o instituciones de la administración pública no puedan emprender acciones sobre la base del contenido del informe.

En El Salvador, lo concerniente a los informes de las comisiones de investigación se encuentra plasmado en los ordinales 32 y 37 del Artículo 131 de la Constitución, y en el Artículo 55 del reglamento interior de la Asamblea Legislativa:

Ordinal 37. Recomendar a la Presidencia de la República la destitución de los Ministros de Estado, o a los organismos correspondientes; la de los funcionarios de Instituciones Oficiales Autónomas cuando así lo estime conveniente, como resultado de la investigación de sus comisiones especiales o de la interpelación, en su caso. La resolución de la Asamblea será vinculante cuando se refiera a los jefes de seguridad pública o de inteligencia de Estado por causa de graves violaciones de los Derechos Humanos.

Artículo 55. Concluido el trabajo de investigación, las comisiones especiales emitirán el informe correspondiente para que la Asamblea adopte los acuerdos o recomendaciones que estime necesarios, conforme lo establecen los ordinales 32 y 37 del Art. 131 de la Constitución, según sea el caso.

En la actualidad, una de las características de la asamblea en El Salvador es la inexistencia de subcomisiones; otra la constituye el hecho de que las comisiones de investigación prácticamente no han existido porque si el Legislativo era corrupto, para qué iba a investigar a los Poderes Judicial y Ejecutivo si allí reinaba impunemente la corrupción. Los tres Poderes del Estado históricamente han sido utilizados, así como también los militares, por la oligarquía como fuente de enriquecimiento ilícito e instrumentos para mantener en la miseria, el analfabetismo, el desempleo, la represión y explotación, entre otros, a la población de Cuscatlán. Esta es una de las explicaciones del porqué de la

41. Solis Fallas, Alex. El control parlamentario, San José, PRODEL, 1995, p. 124. 
inexistencia de tales entidades, sin embargo, existe la posibilidad de crearlas pero no para que investiguen, pues la derecha se ha preocupado para que éstas no tengan condiciones ni apoyo para descubrir la verdad. Quiere decir que si le otorgan las facultades y los recursos a las comisiones de investigación para que hagan su trabajo tal y como debe ser, los primeros que protestarían directa o indirectamente serían los corruptos, es decir, todos aquellos que han hecho su fortuna robando a través de algún Poder del Estado o institución de la Administración Pública. Ejemplo de ello serían los militares o ex miembros de la izquierda que se enriquecieron durante la guerra; los lacayos de las multinacionales, narcotraficantes, delincuentes del crimen organizado, etc. Todas estas personas se opondrán en nombre del pueblo y la democracia, porque en nombre de estas entidades han cometido todas las barbaridades que ha sufrido y sufre la población de este país desde la conquista y la colonización. 